In press, Journal of Experimental Psychology: General

(C) 2018, American Psychological Association. This paper is not the copy of record and may not exactly replicate the final, authoritative version of the article. Please do not copy or cite without authors' permission. The final article will be available, upon publication, via its DOI: $10.1037 / x g e 0000537$

\title{
The Dark Side of Morality: Prioritizing Sanctity Over Care Motivates Denial of Mind and Prejudice Toward Sexual Out-Groups
}

\author{
Andrew E. Monroe ${ }^{1 *} \&$ E. Ashby Plant ${ }^{2}$ \\ ${ }^{1}$ Appalachian State University, ${ }^{2}$ Florida State University
}

\begin{abstract}
Moral values bind communities together and foster cooperation; yet, these same values can lead to the derogation and marginalization of outgroups. Five studies test a theoretical framework proposing that preferentially endorsing moral values of sanctity versus care (the sanctity-care tradeoff) produces a motivational bias whereby people perceive sexual outgroup members as less human. This denial of mind, in turn, legitimizes expressions of prejudice and discrimination toward sexual outgroups. Study 1 showed that natural variations in people's moral values predicted denial of mind and prejudice. Study 2 replicated this pattern, examining political liberals and conservatives, and demonstrating that moral values and denial of mind help explain the relationship between personal politics and prejudice. Study 3 measured people's moral values by examining people's willingness to tradeoff a moral value for money and used this measure to predict denial of mind, prejudice, and decreased willingness to help transgender individuals. Study 4 used religion to boost sanctity values and found a corresponding increase in denial of mind and prejudice. Finally, Study 5 reduced denial of mind and prejudice by intensifying concerns about care. Together, these studies demonstrate that moral values importantly influence how people decide who possesses a mind and is entitled to moral rights, and who is mindless and allowed to be hurt or neglected.
\end{abstract}

Keywords: Morality; Moral Foundations; Prejudice; Mind perception; Person Perception

*Correspondence to:

Andrew E. Monroe

Department of Psychology

Appalachian State University

222 Joyce Lawrence Ln.

Boone, NC 28608, USA

E-mail: monroeae1@appstate.edu 


\section{The Dark Side of Morality: Prioritizing Sanctity Over Care Motivates Denial of Mind and Prejudice Toward Sexual Out-Groups}

Morality is a unique and potent force in human social life. Problematically, however, people often disagree upon what counts as moral, and these disagreements have important implications for people's behavior, their perception of others, and their beliefs about society at large. Recently, Graham and colleagues (Graham et al., 2011; Haidt \& Graham, 2009) suggested the existence of five distinct moral domains: care, fairness, loyalty, authority, and sanctity. However, across and within cultures, people disagree about whether these values are moral or matters of social convention (Turiel, Killen, \& Helwig, 1987); people clash over which values ought to take precedence over others (Graham, Haidt, \& Nosek, 2009; Haidt \& Graham, 2009), or whether multiple moral values exist at all (Schein \& Gray, 2017). Disagreements over how to carve up the moral domain have been linked to everyday decisions about sharing, reciprocity, and deception (Dungan, Waytz, \& Young, 2014; Dungan \& Young, 2015; Waytz, Dungan, \& Young, 2013), as well as people's attitudes about hot-button issues (e.g., suicide; Rottman, Kelemen, \& Young, 2014) and "culture war" disputes (e.g., gay rights, abortion, flag burning; Koleva, Graham, Iyer, Ditto, \& Haidt, 2012).

Among the most contentious culture war issues are disputes regarding the treatment of sexual outgroups (e.g., LGBTQ+ individuals, or people with AIDS). In these debates, the moral values of sanctity and care play outsized roles in shaping people's perspective and behaviors. For example, Koleva and colleagues (2012) demonstrated strong and opposite associations between attitudes about gay marriage and care and sanctity values. Care predicted more favorable attitudes toward same-sex relations and gay-marriage. Conversely, valuing sanctity predicted disapproval of both. Despite these patterns, however, the causal mechanisms linking moral values to expressions of sexual-outgroup prejudice remains unclear.

The present work offers a motivational framework to explain the effects of moral values - specifically sanctity and care — on prejudice toward sexual outgroup members. Sanctity values are associated with condemning acts and individuals viewed as socially or spiritually contaminating (e.g., act/people viewed as disgusting, unnatural, or base). By contrast, care values lead people to disapprove of individuals who cause suffering without just cause (Haidt, 2008; Haidt \& Graham, 2007). We focus on these two values because they suggest opposing motivations for perceiving and behaving towards sexual outgroup members, and we adopt a broad definition of sexual outgroups to include groups that have historically suffered from discrimination because of their sexual orientation (gay men), sexual identity (transgender individuals), or stereotypes about their sexual behaviors (sex workers, people with AIDS).

Our core theoretical prediction is that when people place greater emphasis on sanctity (relative to care), it motivates a biased, dehumanizing perception of sexual outgroup members' minds. Indeed, in defining sanctity Haidt and Graham (2007) suggest the individuals perceived as violating sanctity values are viewed as "debased, impure, and less than human" (p. 106); by contrast, care values are associated with simulating the minds of others (Hasson, Tamir, Brahms, Cohrs, \& Halperin, 2018). In this way, variations in people's tendency to grant or deny fullyhuman minds to sexual outgroup members may be a crucial step linking moral beliefs and prejudicial behavior. Anecdotal examples, history, and recent empirical research indicate that entities perceived as lacking a mind are not viewed as entitled to moral rights and protections (Gray, Gray, \& Wegner, 2007; Gray, Young, \& Waytz, 2012; Haslam, 2006). Thus, we argue that the tendency to dehumanize sexual outgroups motivates and legitimizes expressions of prejudice and discrimination. We refer to this prediction as the "sanctity-care tradeoff" because it 
specifies that the interplay between sanctity and care values (i.e., prioritizing sanctity verses care) motivates denial of mind and downstream expressions of prejudice. Below we derive the evidential basis for this prediction and outline possible alternative models.

\section{Morality is multifaceted and sometimes values compete}

Early research on morality characterized people's moral values as singularly dominated by concerns about care and justice (Gilligan, 1982; Kohlberg, 1976; Piaget, 1965; Turiel, 1983). Recent work however, suggests that human morality is comprised of five distinct domains (or foundations) of moral concern: care, fairness, sanctity, in-group loyalty, and respect for authority (Graham et al., 2011, 2009; Haidt \& Graham, 2009; Haidt \& Joseph, 2008). Each of these distinct values are widely held across cultures (Graham et al., 2011; Yilmaz, Harma, Bahçekapili, \& Cesur, 2016), and are thought to correspond to different virtues and violations (c.f. Schein \& Gray, 2017 for an alternative monist account of morality). ${ }^{1}$ Specifically, care values are closely associated with protecting vulnerable individuals (e.g., the poor; Low \& Wui, 2015), increased helping (Niemi \& Young, 2013), inhibiting interpersonal aggression (e.g., antagonism and spite; Noser et al., 2015; Zeigler-Hill, Noser, Roof, Vonk, \& Marcus, 2015), and increased concern for the suffering of others (Graham et al., 2011). Critically, for the present studies, care values are also associated with more empathy for others and extending empathy to a wider range of people (Hasson et al., 2018; Waytz, Iyer, Young, \& Graham, 2016).

By contrast, sanctity motivates people to protect the self and close others from contamination, and it motivates people to condemn (and potentially hurt) people perceived as physically contaminating or morally degraded (e.g., lacking self-control). For example, sanctity concerns are heightened when disease is regionally prevalent (Van Leeuwen, Koenig, Graham, \& Park, 2014; Van Leeuwen, Park, Koenig, \& Graham, 2012), and sanctity concerns are associated with dislike of potentially contaminated others, predicting increased disliking for the poor (Low \& Wui, 2015) and higher acceptance of torture and lower willingness to help foreigners (Smith, Aquino, Koleva, \& Graham, 2014). Critically, for the present studies, sanctity values are also associated with perceptions others' minds - specifically self-control — and moralizing perceived failures of control (e.g., behaving lewdly, lustily or impulsively) (Mooijman et al., 2017).

Our perspective suggests that, within the context of perceiving and behaving toward sexual outgroups care and sanctity values are in tension with one another. Sanctity with its emphasis on contamination (e.g., "I would call some acts wrong on the grounds that they are unnatural.") and self-control may motivate people to perceive individuals who violate sanctity values (e.g., having 'deviant' sex) as less human (Haidt \& Graham, 2007). Care, however, may be a general counter to these motivated perceptions, as it forbids harm, values vulnerable individuals (e.g., "Compassion for those who are suffering is the most crucial virtue."), and motivates extending empathetic concern to a wider range of people (Hasson et al., 2018; Waytz et al., 2016). Work by Smith and colleagues (2014) conceptually supports this prediction. They demonstrate that having a strong moral identity - a construct related to having an expansive circle of moral care (Reed \& Aquino, 2003) — countered the impact of binding moral foundations (i.e., sanctity, authority, loyalty) on endorsement of torture or refusing to help foreigners.

${ }^{1}$ The present work is agnostic with regard to Schein and Gray's moral reductivism argument. Instead, we endorse the view that even if moral values ultimately reduce into harm, people nonetheless believe there to be meaningful differences in the content of their moral values, and these beliefs motivate behavior (Koleva, Graham, Iyer, Ditto, \& Haidt, 2012) and can — at least for laypeople — conflict with one another (Waytz, Dungan, \& Young, 2013). 
Thus, we propose that differences in the degree to which people endorse sanctity and care will predict perceptions of sexual outgroups' minds as well as discriminatory attitudes and behaviors toward sexual outgroup members. For example, a perceiver might believe that being gay violates a moral value of sanctity, and therefore be predisposed towards viewing gay people as less human, engaging in prejudicial behavior, and supporting discriminatory public policies. However, if the perceiver simultaneously endorses a moral value of care-believing that people have a right to be protected from physical or psychological harm - this value may blunt the prejudicial tendencies primed via sanctity beliefs.

Our focus on the relative weighting of competing moral values is supported by recent work on whistleblowing. In a whistleblowing dilemma, people must decide whether to report their company's unethical behavior to a third party (prioritizing fairness) or to protect their company by keeping silent (prioritizing loyalty). Waytz and colleagues (2013) demonstrated that people's dispositional tendency to value fairness versus loyalty, as well as experimental inductions to prioritize fairness values, increased people's willingness to engage in whistleblowing. Thus, previous research provides evidence that moral tradeoffs can affect specific behavioral choices (e.g., whistleblowing); however, no work to date has examined whether tradeoffs between moral values can affect broader patterns of behavior, namely whether people's moral values, and the tradeoffs between, them can motivate dehumanization and prejudice toward groups of people.

\section{Moral values may motivate mind perception}

Critical to our model is the assertion that moral values inform how people perceive the minds of others. Of course, moral values provide a template for evaluating which behaviors are permitted or prohibited (Janoff-Bulman \& Carnes, 2013; Janoff-Bulman, Sheikh, \& Hepp, 2009; Rai \& Fiske, 2011), but morality may also provide a template for who is deserving of a mind (Gray et al., 2012). Our view is that sanctity and care oppositely motivate perceptions of sexual outgroup members' minds. On the one hand, consistent with past research demonstrating an association between sanctity and moralizing failures of self-control (Haidt \& Graham, 2007; Mooijman et al., 2017), sanctity values may exert a dehumanizing effect toward sexual outgroup members. On the other hand, care, may exert a humanizing effect, as past research demonstrates that care strengthens the depth and breadth of people's attempts to empathize with others (Hasson et al., 2018; Waytz et al., 2016).

Our study is the first to examine whether people's moral values motivate perceptions of others minds; however, the research is replete with examples where people's moral judgments influence inferences about others' mind, including effects on perceived intentions (Cova, Lantian, \& Boudesseul, 2016; Knobe, 2003), desires (Pettit \& Knobe, 2009), knowledge (Beebe \& Buckwalter, 2010), values, and even evaluations of a person's free will (Phillips \& Knobe, 2009). Recent neuroscientific work dovetails with these findings. Harris and Fiske (2006) used fMRI to show that people perceived as moral reprobates (e.g., drug addicts, sex workers, the homeless) are dehumanized even at the neural level. They show that morally deviant targets elicited lower patterns of activation in the medial pre-frontal cortex (mPFC, an area necessary for social cognition) and higher patterns of activation in the insula and amygdala (areas associated with disgust reactions) compared to control targets.

Importantly, several recent studies suggest that this tendency to deny minds is motivated and that it is not explained merely by differences in liking one's ingroup more than the outgroup. Tendayi et al. (2006) demonstrated that, controlling for ingroup favoritism and liking, people 
more easily associate outgroups with animal-related words compared to ingroups. Further, recent work by Kteily, Hodson and Bruneau (2016) reveals that high-status groups engage in motivated dehumanization in order to maintain the status quo and defend against perceived threats from low-status groups. Finally, Haslam (2006) brings the connection between moral values and dehumanization into sharp focus, arguing that, "When an outgroup is perceived to have dissimilar values to the ingroup, it is perceived to lack shared humanity and its interests can be disregarded" (p. 255). Although none of these studies show that perceivers fully deny minds to human targets, they consistently show a pattern whereby values influence the way people ascribe minds and mental states to others.

\section{Denial of mind legitimizes prejudice}

Denial of mind may be a crucial step between people's moral beliefs and their behavior. In general, humans have a strong aversion to harming other humans (Cushman, Gray, Gaffey, \& Mendes, 2012); however, the belief that a person is "no better than an animal" is a potent justification for allowing (or endorsing) harm. In one empirical demonstration of this phenomenon, Myers, Godwin, Latter, and Winstanley (2004) examined the effect of relative dehumanization on mock jurors' death penalty decisions. Jurors were presented with identical cases accompanied by a brief victim statement. The content of the statement either humanized the victim (e.g., describing the personal qualities of the victim), dehumanized the perpetrator (e.g., describing him in animalistic terms), or did neither. Whereas humanizing the victim did not affect sentencing decisions, dehumanizing the perpetrator resulted in jurors becoming significantly more likely to recommend the death sentence for the perpetrator.

Similarly, for mundane behaviors, perceiving a person as relatively less human increases blame (Bastian, Denson, \& Haslam, 2013) and decreases praise (Bastian, Laham, Wilson, Haslam, \& Koval, 2011). These findings are consistent with Opotow's (1990) work on "moral exclusion" whereby denying a person a fully-human mind legitimizes harm by placing her "outside the boundary in which moral values, rules, and considerations of fairness apply" (p. 1). Relative differences in people's attributions of a mind to an agent predict their willingness to harm it (Gray et al., 2007), and the degree to which people deny a mind to an entity increases people's acceptance of harm to it (Bastian, Loughnan, Haslam, \& Radke, 2012).

A consistent theme in this work is that likening people to animals increases tolerance or endorsement of harm toward these people. Importantly, dehumanization does not require a complete denial of mind. Rather denial of mind (especially to humans) is a matter of subtle degrees. Moreover, people can deny minds to others in two distinct ways (Cikara, Eberhardt, \& Fiske, 2011; Haslam, 2006; Haslam \& Loughnan, 2014). They can deny that a person possesses what Haslam (2006) terms basic human nature $(\mathrm{HN})$ : characteristics associated with phenomenological mental states (e.g., fear, hunger, desire, pleasure). Dehumanization of this type is characterized as thinking of a target as cold or robotic. Alternatively, people can deny that a target possesses Uniquely Human (UH) characteristics associated with higher-order cognition, rational planning, and self-control. This form of dehumanization is characterized by thinking of a target as relatively more animalistic and unable to inhibit behavior. As noted above sanctity values are associated with moralizing perceived failures of self-control and perceiving others as driven by wanton, animalistic urges. Thus, we predict that the sanctity-care tradeoff will predict dehumanization in terms of denying UH characteristics (i.e., higher-order reasoning, self-control, rationality); whereas, ascriptions of a phenomenological mind (basic human nature HN) will be 
unaffected. Moreover, we predict that the relative denial of a UH mind will mediates the relationship between people's moral values and prejudice toward sexual out-groups.

Previous research on racial prejudice links the relative denial of UH characteristics to prejudice. In some racist descriptions, Black people, particularly Black men, are compared to apes and sometimes explicitly denied membership of the human species. Goff and colleagues (Goff, Eberhardt, Williams, \& Jackson, 2008) demonstrated that activating the implicit association between Black men and apes leads to increases acceptance of aggressive policing tactics, including finding it more acceptable for police officers to assault a Black suspect. In addition, the more law enforcement officers associated Black people with apes, the more they had used force against Black children compared to children of other races (Goff, Jackson, Di Leone, Culotta, \& DiTomasso, 2014). In the context of sexism, Rudman and Mescher (2012) found that men who denied women UH characteristics were more tolerant of sexual harassment and rape than men who did not dehumanize women. Together, this research clearly demonstrates that relative denial of mind motivates, explains, and in some cases, legitimizes prejudicial attitudes and behaviors. Critically, however, our motivational framework extends this research by testing whether people's moral values influence denial of mind and subsequent prejudicial attitudes and behaviors.

\section{Overview of the present studies}

In this paper, we examine the moral roots of prejudice against sexual outgroups. We hypothesize that preferentially endorsing sanctity over care results in a motivational bias whereby people perceive sexual outgroup members as possessing a less human mind, and this tendency to dehumanize, in turn, legitimizes expressions of prejudice and discrimination.

Specifically, two key predictions guide this research. First, we predict that the relative endorsement of sanctity compared to care-what we refer to as the sanctity-care tradeoff-will increase dehumanization (i.e., denial of a rational mind) and expressions prejudice towards sexual out-groups. Second, because dehumanization legitimizes hostility, we predict that the denial of a rational mind to sexual outgroup targets will mediate the relationship between the sanctity-care tradeoff and expressions of prejudice and discrimination.

Whereas the main goal of the current research is to test the claims of our model, we also examine an alternative prediction postulating that people's political orientation, not their moral values, explains denial of mind and prejudice against sexual outgroups. This explanation postulates that because issues surrounding LGBTQ+ rights (and sexuality more broadly) have become so heavily politicized, people's attitudes on these issues reflect political partisan loyalties rather than personal values. This alternative model would predict that, a person's political orientation should predict denial of mind and prejudice, whereas the sanctity-care tradeoff should not explain any unique variance when controlling for political orientation. By contrast, we propose that although people's political beliefs certainly impact their attitudes toward sexual outgroups, moral values retain important, independent explanatory value.

Five studies examined the link between moral values and denial of mind and prejudice toward sexual outgroups. Study 1 used a correlational approach to show that people with a larger sanctity-care tradeoff were more likely to deny rational minds to people who were gay or who have sexually transmitted diseases (AIDS). Study 2 collected data from self-identified conservatives and liberals and demonstrated that conservatives were more likely to endorse a sanctity-based relative to care-based morality. These moral values, not political orientation, then predicted denial of mind, prejudicial attitudes, and endorsing discriminatory public policies. 
Study 3 replicated our findings using an alternative measure of moral values: taboo tradeoffs (Tetlock, Kristel, Elson, Green, \& Lerner, 2000) and extended our findings to an additional sexual outgroup target: transgender individuals. Study 4, used a religious manipulation to prime sanctity values. We measured people's endorsement of sanctity and care, denial of mind, and expressions of prejudice on either a religious holiday (Ash Wednesday) or on a non-religious day. Participants tested on Ash Wednesday reported higher endorsement of sanctity values, and subsequently stronger denial of mind and prejudice toward a sexual outgroup member compared to participants surveyed on a non-religious day. Finally, Study 5 manipulated concerns about care values and showed that heightening care, relative to sanctity, led to subsequent reductions in denial of mind and prejudice toward gay and transgender targets. For all studies, we report all manipulations and dependent measures. Each study's sample size and stopping rules were determined prior to data collection.

\section{Ethics Statement}

The Florida State University and Appalachian State University Institutional Review Boards approved the ethics of all of the following studies. All participants were 18 years of age or older and provided written informed consent using an electronic form (Studies 1-3, 5) or verbally consented to participating in the experiment (Study 4).

\section{Study 1}

This study tested two key hypotheses. First, we hypothesized that the strength of endorsement of sanctity relative to care would result in the denial of a rational mind for sexual outgroup targets (i.e., people with AIDS, gay men). Second, we predicted that denial of mind would positively predict prejudice and mediate the relationship between sanctity-care and expressions of prejudice toward the gay and AIDS targets. Lastly, we sought to demonstrate that the effect of the sanctity-care tradeoff on dehumanization and prejudice is specific to sexual outgroup targets. We therefore included three control targets in this experiment: two targets who belong to commonly marginalized groups (i.e., African American and obese targets) and a majority group target (i.e., a White male). We predicted that the sanctity-care tradeoff would not predict dehumanization and prejudice for these groups.

\section{Methods}

\section{Participants}

Prior to initiating data collection, we conducted a power analysis $\left(\mathrm{G}^{*}\right.$ Power, linear multiple regression) to determine our sample size. As this was the first test of our model, we assumed a small effect size $\left(r^{2}=0.05\right)$ and computed for a desired power of 0.95 . The analysis revealed a required sample size of 249 participants; however, as the Study was online with Amazon Mechanical Turk (MTurk) participants, we elected to oversample to ensure sufficient power. Our stopping rule for data collection was to recruit 300 participants.

In total 16 participants failed to complete the study resulting in a final sample of 284 participants. The majority of participants in the sample were female $(n=134)$ and White $(n=$ 199), with smaller numbers of participants identifying as African American $(n=32)$, Asian $(n=$ $29)$, Latino $(n=15)$, Native American $(n=7)$, or Middle Eastern $(n=2)$. The sample was politically moderate $(M=3.28, S D=1.62)$ based on a 1 (very liberal) - 7 (very conservative) 
scale, and participants reported being moderately religious on average $(M=2.46, S D=1.50)$ on a 1 (not at all religious) - 5 (very religious) scale.

\section{Procedure}

After consenting to participate, participants completed the Moral Foundations Questionnaire (MFQ, Graham et al., 2009). This scale measures the degree to which people endorse five independent moral values: care $(\alpha=.69)$, fairness $(\alpha=.69)$, sanctity $(\alpha=.87)$, loyalty $(\alpha=.78)$, and authority $(\alpha=.75)$, using a $1-6$ Likert scale where higher scores reflect stronger endorsement of a particular moral value and lower scores reflect rejecting a value as having moral import.

After completing the MFQ, participants read and made judgments about five different male targets: a gay man, a man with AIDS, an African American man, an obese man, and a White man. The descriptions included only the agent's name, age, profession, and short description of the manipulation-relevant personal characteristic (e.g., "John Radcliff, 32, works as an industrial designer. He is attracted to other men and identifies as gay."). The agent descriptions were intentionally designed to be sparse in order to allow participants to fill in ambiguities with personally held beliefs about the social group (e.g., gay men). The order of the agent descriptions was counterbalanced across participants, with the exception that the White agent was always presented last.

For each agent, participants responded to a six-item dehumanization measure (Haslam, 2006; Haslam, Loughnan, Kashima, \& Bain, 2009). This questionnaire contained three questions measuring denial of a rational mind (e.g., "John is rational and logical," [reverse scored] $\alpha=.84$ ) and three items measuring denial of basic human emotions (e.g., "John is rigid and cold," $\alpha$ $=.92$ ) each scored on a 1 (not at all) to 7 (extremely) Likert scale. Higher scores on these measures indicated more denial of mind. Following this measure, participants used a feelings thermometer to indicate their feelings of warmth towards the target ( 0 very cold -10 very warm), and participants answered three questions tapping attitudes toward the targets ("Would you want to be friends with [target]?" "Would you want to wear [target]'s sweater?" "If given the chance, I would stand up for [target]."), using a 1 (definitely no) - 5 (definitely yes) Likert scale. We combined the scores from the feelings thermometer and the attitude questions into a single variable assessing the positivity of people's attitudes toward each target, where lower scores correspond to more negative attitudes $\left(\alpha_{\text {gay }}=.88, \alpha_{\text {AIDS }}=.82, \alpha_{\mathrm{AA}}=.81, \alpha_{\text {obese }}=.81\right.$, $\alpha_{\text {White }}$ $=.80)$.

\section{Results}

\section{Do Moral Values Predict Denial of Mind?}

We created the sanctity-care tradeoff by subtracting participants' average care score on the MFQ from their sanctity score (i.e., sanctity - care). Thus, higher scores indicate comparatively stronger endorsement of sanctity relative to care. We then used this variable to predict the denial of a rational mind to each target. ${ }^{2}$ Regression analyses confirmed our first

${ }^{2}$ Though care and sanctity showed the same descriptive predictive patterns as the sanctity-care tradeoff, across studies care and sanctity considered independently were weaker and less consistent predictors of the dependent measures compared to the sanctity-care tradeoff. Additionally, the sanctity $\mathrm{x}$ care interaction inconsistently predicted dehumanization and failed to predict prejudice (See Supplementary Analyses). Moreover, because people typically endorse both sanctity and care to some degree, it is important to consider their effect in tandem - because that is 
prediction. People who more strongly endorsed sanctity, relative to care, were more likely to deny a rational mind to the gay target, $\beta=.22, t(282)=3.81, p<.001$ as well as the target with AIDS, $\beta=.22, t(282)=3.82, p<.001$. The sanctity-care tradeoff did not, however, predict denial of mind to obese targets, $\beta=.07, t(282)=1.21, p=.23$, African American targets, $\beta$ $=.095, t(282)=1.61, p=.11$, or White targets, $\beta=.06, t(282)=1.00, p=.32$. Consistent with our predictions, denial of mind was limited to denying a rational mind to targets. The sanctitycare tradeoff did not predict whether people denied targets basic human nature (e.g., being able to feel emotions or other low-level sensations), $\beta \mathrm{s}<.09, p \mathrm{~s}>.15$.

Additionally, a follow up analysis tested whether the sanctity-care tradeoff remained a significant predictor of denial of mind controlling for participants' political identification and other moral values (i.e., fairness, loyalty, authority). A multiple regression with politics, fairness, loyalty, authority, and the sanctity-care tradeoff revealed that the sanctity-care tradeoff remained a significant predictor of denial of mind for both the gay $(\beta=.20, p=.027)$ and the AIDS targets $(\beta=.20, p=.026)$. By contrast, none of the other moral values significantly predicted denial of mind for either target $(\beta \mathrm{s}<.14, p \mathrm{~s}>.16)$, and politics marginally predicted denial of mind for the gay target $(\beta=.13, p=.064)$, but did not predict denial of mind for the AIDS target $(\beta=.109, p=.124)$.

\section{Moral Values and Denial of Mind Predicting Prejudicial Attitudes}

As can be seen in Figure 1, the sanctity-care tradeoff was a significant predictor of attitudes toward the gay and AIDS targets. We next tested whether the effect of people's moral values on their attitudes towards the targets was mediated by denying rational minds to those targets. We conducted separate mediation models for each of the five targets using Hayes' (2013) PROCESS macro (model 4) with 10,000 bootstrapped samples. As predicted, denial of mind partially mediated the relationship between sanctity-care tradeoff and attitudes towards both the gay target, indirect $b=-0.101, s e=.027,95 \% \mathrm{CI}[-0.160,-0.052]$, and the target with AIDS, indirect $b=-0.087$, se $=.025,95 \%$ CI [-0.142, -0.044] (See Figure 1). By contrast, the mediation models for the other three targets were not significant: African American, indirect $b=$ $-0.029,95 \%$ CI [-0.070, 0.004], obese, indirect $b=-0.029,95 \%$ CI [-0.076, 0.016], and White targets, indirect $b=-0.020,95 \%$ CI [-0.063, 0.016], suggesting that the sanctity-care effect on dehumanization and prejudice is specific to the sexual outgroup targets.

Additionally, we tested two reverse mediation models (1) attitudes $\rightarrow$ denial of mind $\rightarrow$ sanctity-care and (2) attitudes $\rightarrow$ sanctity-care $\rightarrow$ denial of mind for both sexual outgroup targets. None of the alternative models, however, were significant. Testing the first alternative model showed nonsignificant mediation for the gay and the AIDS targets, indirect $b_{\text {gay }}=-0.030$, $s e=.050,95 \%$ CI [-0.128, 0.071]; indirect $b_{A I D S}=-0.072, s e=.051,95 \%$ CI [-0.173, 0.028$]$. Similarly, tests of the second alternative model were nonsignificant, indirect $b_{A I D S}=-0.021$, se $=.016,95 \%$ CI [-0.058, 0.006]; indirect $b_{\text {gay }}=-0.010, s e=.017,95 \%$ CI [-0.043, 0.024].

Lastly, follow up analyses demonstrated that our mediation models survived controlling for participants' political orientation and endorsement of other moral values. Denial of mind remained a significant mediator of the relationship between sanctity-care and attitudes towards the gay target, indirect $b=-0.091, s e=.043,95 \% \mathrm{CI}[-0.178,-0.012]$, and the target with AIDS, indirect $b=-0.079, s e=.035,95 \%$ CI $[-0.150,-0.012]$. Politics also emerged as a significant

how they exist in people's minds. Although we would expect both care and sanctity to predict denial of mind and prejudice, it is more parsimonious and consistent with our theorizing to look at them together. 
predictor of attitudes toward targets $(p s<.05)$, but as noted above, failed to significantly predict denial of mind. Similarly, none of the other moral values predicted attitudes toward the targets $(p \mathrm{~s}>.1)$.
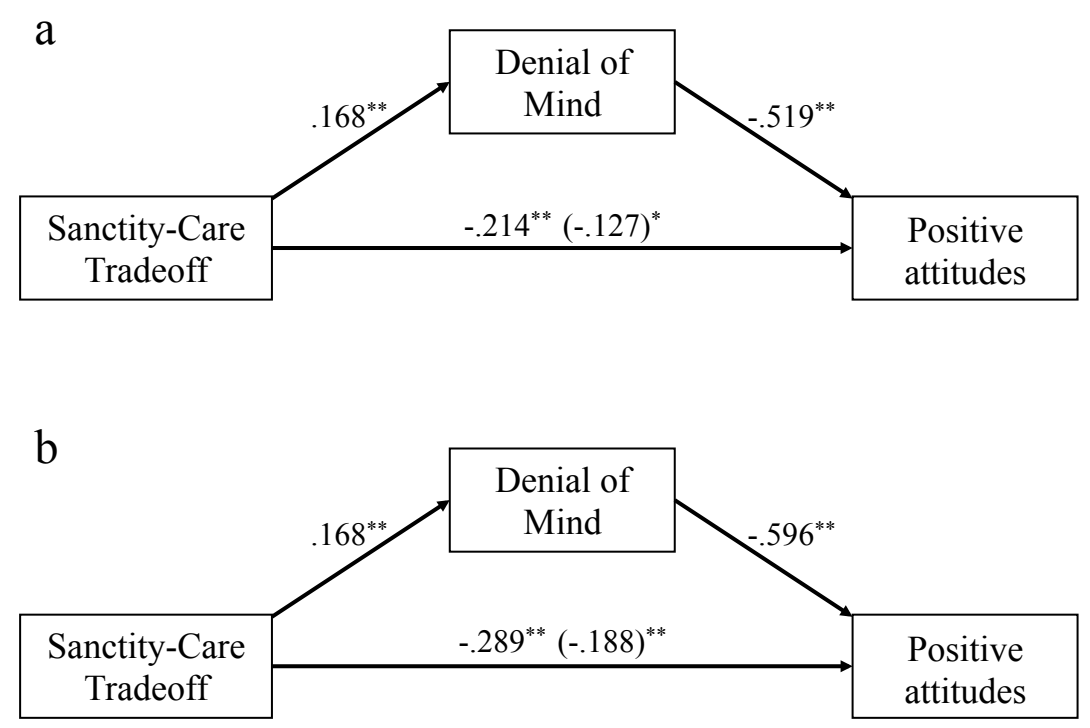

Figure 1. Unstandardized path coefficients. Denial of a rational mind mediates the relationship between moral values (sanctity-care tradeoff) and attitudes towards people with AIDS (panel a) and gay men (panel b). $*=p \leq .01, * *=p<.001$.

\section{Discussion}

Study 1 examined the natural variation in people's moral values and showed that people who more strongly emphasized sanctity-related moral values relative to care values were more likely to view members of a sexual outgroup (e.g. a gay man or a person with AIDS) as lacking uniquely human traits such as possessing a rational mind and self-control. Moreover, we demonstrated that our effects persisted even after controlling for participants' political orientation as well as their endorsement of other moral values (fairness, loyalty, and authority).

Additionally, this study demonstrated two theoretically-relevant limits to its effects. First, consistent with our predictions, moral values did not predict denial of basic human nature (e.g., fear, hunger, desire, pleasure). Rather, our effect was uniquely focused on denying rational minds to targets (e.g., intentional planning, rationality, self-restraint). Thus, the data suggest that the sanctity-care tradeoff motivates a specific bias whereby people perceive sexual outgroups more like animals driven by slavish desires than fully rational, human agents. Second, we demonstrate that the sanctity-care tradeoff only predicted denial of mind for sexual outgroups (i.e., people with AIDS, gay men) and not a general tendency to deny minds to any marginalized targets (i.e., obese or African American targets) or majority-group target (i.e., a White men). Thus, we demonstrate the effect of moral values on prejudice is specific to those groups for whom the moral values are salient (i.e., sexual outgroups) rather than being a general negativity effect.

Lastly, our findings demonstrate that the sanctity-care tradeoff is a unique predictor of bias. No other moral values (fairness, authority or loyalty) were related to either denial of mind or prejudicial attitudes. Further, personal political orientation was an uneven predictor, failing to 
predict denial of mind, but still predicting prejudicial attitudes. Critical to our theory, however, the sanctity-care tradeoff explained unique variance even when controlling for political orientation and other moral values.

\section{Study 2}

Study 2 replicated and extended the findings from Study 1 using a quasi-experimental design. We recruited self-identified liberals and conservatives and tested whether the tendency for liberals and conservatives to dehumanize sexual outgroups could be explained by differences in their moral foundations and, in particular, their relative valuations of sanctity versus care. Two predictions guided this study. We predicted, consistent with previous work on moral foundations (Graham et al., 2011, 2009), that conservative participants would more strongly endorse sanctity relative to care. Critically, however, we predicted that—consistent with Study 1 - differences in the degree to which people endorsed sanctity versus care would predict the denial of mind to sexual outgroups, and this would in-turn predict prejudicial attitudes and discriminatory behavior.

Additionally, we sought to extend the findings from Study 1 by using more traditional measures of outgroup prejudice. Specifically, we used a modified version of the Attitudes toward Blacks scale (ATB; Brigham, 1993) to test if the findings for prejudice toward the target individual from Study 1 generalized to outgroup prejudice more broadly. We anticipated that individuals who deny minds to the person with AIDS and the gay target would also express more prejudice toward those groups more broadly. Additionally, we included a speeded assessment of prejudice to see if our effects would generalize to a measure of prejudice that was difficult to control. This allowed us to test whether the impact of morality and denial of mind was due to differences in the perceived acceptability of prejudice rather than true outgroup negativity. If the perceived acceptability of prejudice was the key factor, then we anticipated that we would not find differences on the less controllable measure as a function of the sanctity-care tradeoff. Finally, we assessed approval of public policies that were relevant to our two sexual outgroups and interest in helping the two sexual outgroups (e.g., attending a rally). These outcomes allowed us to explore whether the impact of morality and denial of mind generalized beyond prejudiced attitudes to policy positions and helping intentions.

\section{Methods}

\section{Participants}

As in Study 1 we conducted an a priori power analysis. Here we drew our effect size estimate from Graham, Haidt and Nosek (2009), which compared liberals' and conservatives' endorsement of different moral values. Using their smallest effect size $(d=0.56$, Study 5$)$ and a desired power of $0.95, G^{*}$ Power (independent samples t-test) indicated a total required sample size of 168 participants.

We therefore recruited 180 participants ( 90 self-identified political liberals and 90 political conservatives) using Amazon Mechanical Turk. To obtain our liberal and conservative samples, we posted two identical HITs, one recruiting self-identified liberals and the other recruiting self-identified conservatives. The HITs were posted simultaneously, and we used intermediary software (TurkGate; Goldin \& Darlow, 2013) to ensure that participants could only complete one version of the study. Stopping rules for data collection were to collect data until $n$ $=90$ for both groups. 
The samples were comparable in age $\left(M_{C o n}=40.3 S D=14.2 ; M_{\text {Lib }}=39.3 S D=14.6\right)$ and ethnic identification: The majority of participants identified as White in both the conservative $(89 \%, n=80)$ and liberal samples $(84 \%, n=76)$, though other demographic differences emerged. There were significantly fewer women in the conservative sample $(n=37)$ than in the liberal sample $(n=51), \chi^{2}(1, \mathrm{~N}=179)=4.70, p=.030$, and conservative participants reported being more religious $(M=3.14 S D=1.41)$ than liberal participants $(M=1.96 S D=1.31), t(178)$ $=5.87, p<.001, d=0.87$ (Scale: $1=$ Not at all religious; $5=$ Very religious).

\section{Procedure}

As in Study 1, participants rated their endorsement of care $(\alpha=.75)$, fairness $(\alpha=.70)$, loyalty $(\alpha=.72)$, authority $(\alpha=.74)$, and sanctity $(\alpha=.88)$ using the MFQ followed by the presentation of the four target persons: a gay person, a person with AIDS, an African American male, and a White male. The target person descriptions were identical to those used in Study 1 and were presented in a random order. For each target, participants responded the six-item dehumanization measure from Study 1, which measured denial of a rational mind $(\alpha=.77)$ and denial of basic human emotions $(\alpha=.86)$. These were followed by three questions tapping positive attitudes toward each target (e.g., "If given the chance, I would stand up for [target]."), using a 1 (definitely no $)-5$ (definitely yes) Likert scale $\left(\alpha_{\text {gay }}=.83, \alpha_{\text {AIDS }}=.87, \alpha_{\mathrm{AA}}=.77, \alpha_{\text {obese }}\right.$ $=.83$, $\left.\alpha_{\text {White }}=.67\right)$.

In addition, we included a modified version of the Attitudes Toward Blacks scale (ATB, Brigham, 1993) and a speeded 10-item semantic differential scale for each of the outgroup targets. The modified ATBs were tailored to each target group (e.g., replacing the word "Black" in the scale question with "gay") and assessed explicit outgroup prejudice by asking participants to indicate their agreement with 10 statements (e.g., "I would rather not have a [Black person/gay person/person with AIDS] live in the same apartment building I live in.") on a 1 (strongly disagree) to 7 (strongly agree) Likert scale $\left(\alpha_{\text {gay }}=.74, \alpha_{\text {AIDS }}=.72, \alpha_{\text {AA }}=.73, \alpha_{\text {obese }}=.68\right)$. The items were averaged so that higher scores indicated more prejudice. The semantic differential scale measured automatic outgroup prejudice (see Kervyn, Fiske, \& Yzerbyt, 2013; Osgood, 1962) by requiring participants to respond quickly to 10 maximally different descriptors (e.g., warm-cold; likable-unlikable) using a $1-7$ Likert scale. The task was time-constrained such that participants had to read and respond to each of the descriptor pairs in 25 seconds or less ( $\alpha_{\text {gay }}$ $\left.=.96, \alpha_{\mathrm{AIDS}}=.97, \alpha_{\mathrm{AA}}=.97, \alpha_{\text {obese }}=.93\right)$. Responses were averaged so that higher scores indicated more automatic prejudice.

After rating all targets, participants responded to four public policy questions relevant to the two sexual outgroups on a 1 (not at all in favor) - 7 (very much in favor) scale. Two of the policies were relevant to gay targets (favoring conversion therapy and national marriage equality legislation [reverse scored], $\alpha=.77$ ) and two were relevant to AIDS targets (favoring ending needle exchanges and mandating AIDS patients register with the government, $\alpha=.48$ ). For each target group we combined the policy questions into a single index so that higher scores indicated stronger endorsement of discriminatory policies.

Finally, participants responded to two measures assessing their willingness to engage in collective action to help each sexual outgroup. These items assessed participants' likelihood of participating in two pro-gay/AIDS awareness activities (i.e., Anonymously donating money to a gay-rights organization; Participating in a nationally-televised rally supporting AIDS awareness) on a 1 (very unlikely) - 7 (very likely). We combined responses to these two questions together into a single helping index for gay $(\alpha=.96)$ and AIDS targets $(\alpha=.90)$. After participants 
responded to all of the dependent measures, they completed a short demographic questionnaire, were debriefed, and provided with a code for payment for their participation.

\section{Results}

\section{Manipulation Check: Liberals' and Conservatives' Moral Values and Dehumanization}

A mixed-model ANOVA comparing liberals and conservatives across the five moral domains (care, fairness, loyalty, authority, and sanctity) confirmed our predicted interaction between political orientation and the moral domains, $F(4,712)=36.2, p<.001, \eta^{2}=.173[95 \%$ CI 0.122, 0.218] (See Figure 2). Pairwise comparisons showed that liberals valued care and fairness more than conservatives ( $p=.009$ and $p<.001$ respectively), whereas conservatives valued loyalty, authority, and sanctity more than liberals $(p s<.001)$. Given these findings, it is not surprising that conservatives tended to score higher on the sanctity-care tradeoff $(M=-0.66$, $S D=1.30)$ than liberals $(M=-2.11, S D=1.37), t(178)=7.23, p<.001, d=1.08,95 \% \mathrm{CI}[0.76$, 1.39].

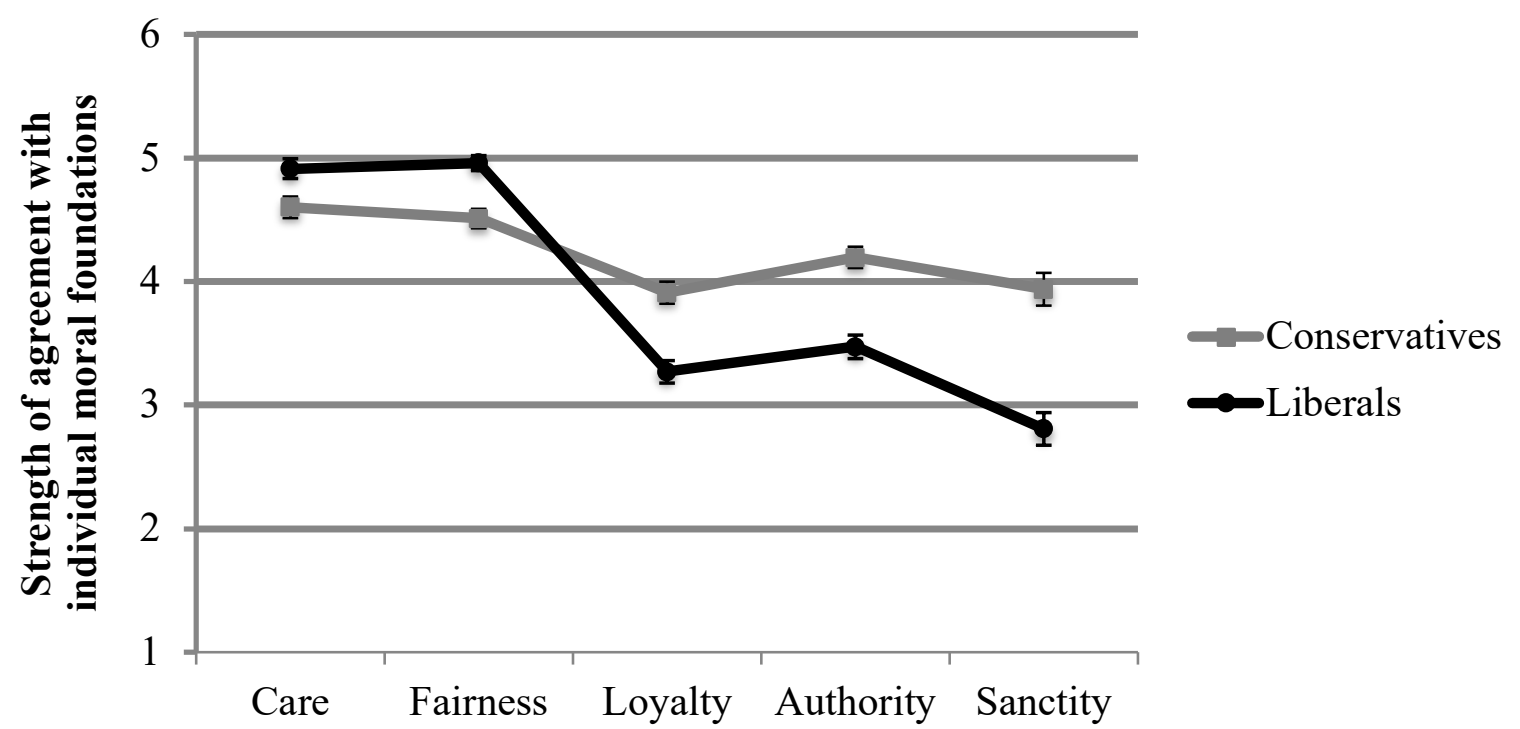

Figure 2. Moral foundation scores for self-identified liberals and conservatives. Liberals value care and fairness as moral values most; whereas, conservatives care similarly about all five foundations. Error bars $= \pm 1 \mathrm{SE}$.

\section{Sanctity-care Tradeoff Predicts Prejudice, Discrimination, and Refusal of Help}

The core prediction of the study was that the sanctity-care tradeoff would predict the relative denial of mind to sexual out-groups, ${ }^{3}$ and this denial of mind would mediate the relationship between moral values and our outcome measures. Across all models, sanctity-care significantly predicted denial of mind for the AIDS target, $b=0.193, p=.0001,95 \%$ CI $[0.100$, $0.289]$ ) and the gay target, $b=0.251, p<.0001,95 \%$ CI $[0.135,0.367]$.

${ }^{3}$ Importantly, the sanctity-care tradeoff failed to predict denial of mind to the Black target, $b=0.009, p=.858,95 \%$ CI [-0.087, 0.104], and none of the mediation models were significant for the Black target, indirect $b \mathrm{~s}<0.005$, [$0.089<95 \%$ CIs $<0.073$ ]. Additionally, other moral values (fairness, loyalty, and authority) failed to predict denial of mind, positive attitudes, and prejudice for the gay and AIDS targets $(p s>.2)$ 
The sanctity-care $\rightarrow$ denial of mind $\rightarrow$ behavioral outcome mediation model (Hayes, 2013, PROCESS model 4 with 10,000 bootstrapped samples) revealed that, for the gay target, denial of mind fully mediated the relationship between sanctity-care and automatic prejudice, and partially mediated for target attitudes, explicit prejudice, discriminatory public policies, and helping intentions, $b s>.084$; ses $<.041 ;$ [ $0.210>95 \%$ CIs $<0.046]$ (See Figure 3). Similarly, for the AIDS target, denial of mind fully mediated the relationship between sanctity-care and automatic prejudice, and partially mediated for target attitudes, explicit prejudice, and helping intentions, $b \mathrm{~s}>.06$; ses $<.041 ;[0.235>95 \%$ CIs $<0.001]$ (See Figure 3$){ }^{4}$
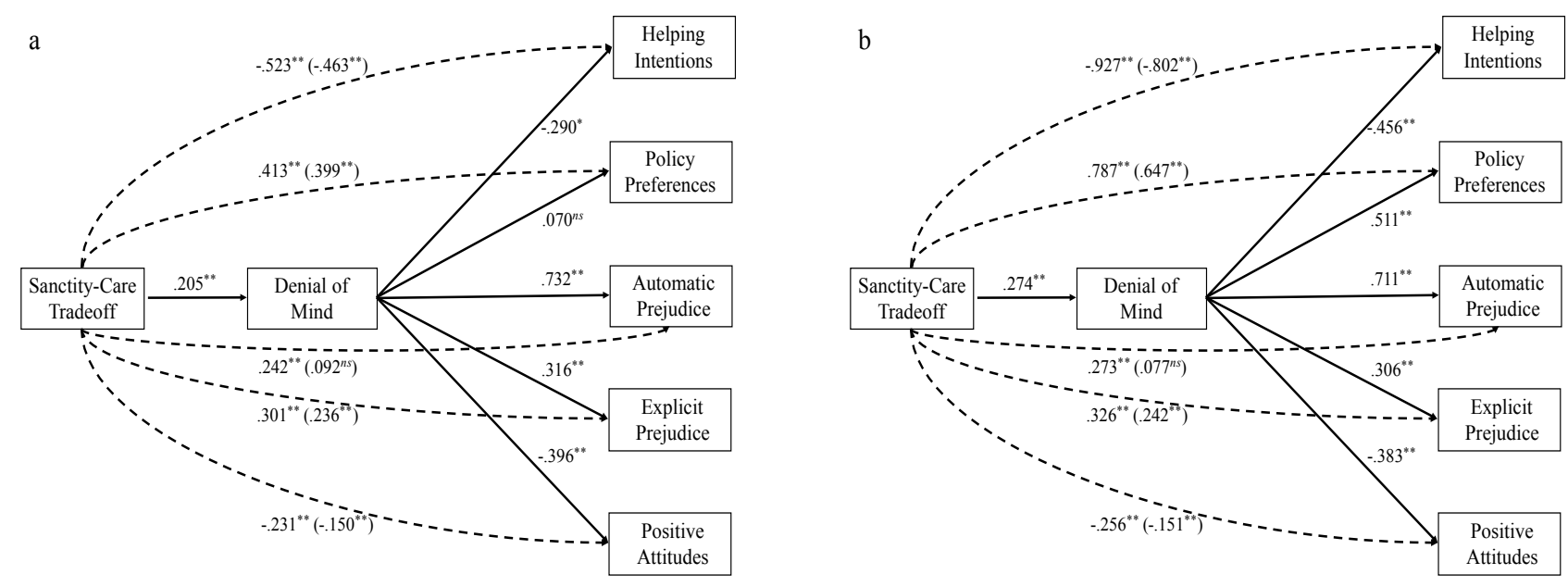

Figure 3. Unstandardized path coefficients predicting dehumanization and prejudice towards AIDS targets (panel a) and Gay targets (panel b). Denial of a rational mind fully mediated the effect on automatic prejudice for both targets, and partially mediated for positive target-directed attitudes, explicit prejudice, discriminatory public policies, and helping intentions, with the exception of AIDS policy preferences. $*=p \leq .01, * *=p<.001$.

After replicating and extending the basic model from Study 1, we wanted to examine whether moral values explain political differences in people's attitudes and behaviors toward sexual outgroups. To test this we used Hayes' (2013) PROCESS macro (model 6) using bootstrapping with 10,000 samples to test a 2-stage, serial mediation model with the following structure: Political orientation $\rightarrow$ sanctity-care tradeoff $\rightarrow$ denial of mind $\rightarrow$ behavioral outcome. This model has the benefit of simultaneously testing a key prediction of our theory - that denial of mind mediates the relationship between moral values and prejudice - while also testing our claim that the sanctity-care tradeoff and denial of mind provide an explanation of the relationship between politics and prejudice against sexual outgroups.

Common across all of the analyses, political orientation (conservatives coded as 0 ; liberals coded as 1) significantly predicted the sanctity-care tradeoff, $b=-1.44, p<.0001,95 \%$ CI [-1.838, -1.049], with political conservatives being more likely to emphasize sanctity versus

\footnotetext{
${ }^{4}$ The one exception to this pattern was predicting AIDS-related policies, where the model was not significant, indirect $b=0.014$, se $=.038,95 \% \mathrm{CI}[-0.054,0.098]$.
} 
care compared to liberals. Additionally, across all models, as noted above, the sanctity-care tradeoff significantly predicted denial of mind for the AIDS and gay targets.

Table 1 details the findings for each of the dependent measures. Overall, the 2-stage mediation analyses confirmed our predictions. For both the AIDS and the gay targets, the route through sanctity-care tradeoff and denial of mind significantly mediated the relationship between politics and people's attitudes towards the targets, explicit prejudice, automatic prejudice, and helping intentions. The only exception to this consistent mediation pattern was for AIDSrelevant public policy preferences where neither the direct effect of politics nor the indirect effects of moral values and denial of mind were significant. ${ }^{5}$

Table 1. Unstandardized Path Coefficients. Moral Values and Denial of a Rational Mind Consistently Mediates the Relationship between Politics, Prejudicial Attitudes, Public Policy Endorsement, and Helping Intentions.

\begin{tabular}{|c|c|c|c|c|c|c|}
\hline & \multicolumn{3}{|c|}{$\begin{array}{c}\text { Indirect Effect of Moral Values } \rightarrow \\
\text { Denial of Mind Pathway }\end{array}$} & \multicolumn{3}{|c|}{ Direct Effect of Politics } \\
\hline & $b$ & se & $95 \% \mathrm{CI}$ & $b$ & se & $95 \% \mathrm{CI}$ \\
\hline \multicolumn{7}{|l|}{ Positive Attitudes } \\
\hline AIDS Target & $0.111^{*}$ & 0.044 & {$[0.043,0.222]$} & 0.045 & 0.126 & {$[-0.203,0.293]$} \\
\hline Gay Target & $0.137^{*}$ & 0.048 & {$[0.061,0.256]$} & 0.226 & 0.133 & {$[-0.036,0.489]$} \\
\hline \multicolumn{7}{|c|}{ Explicit Prejudice } \\
\hline AIDS Target & $-0.089^{*}$ & 0.038 & {$[-0.187,-0.032]$} & 0.012 & 0.125 & {$[-0.234,0.259]$} \\
\hline Gay Target & $-0.108^{*}$ & 0.038 & {$[-0.201,-0.051]$} & $-0.256 *$ & 0.123 & {$[-0.498,-0.014]$} \\
\hline \multicolumn{7}{|c|}{ Automatic Prejudice } \\
\hline AIDS Target & $-0.206^{*}$ & 0.074 & {$[-0.385,-0.090]$} & 0.019 & 0.171 & {$[-0.317,0.356]$} \\
\hline Gay Target & $-0.255^{*}$ & 0.080 & {$[-0.446,-0.124]$} & -0.250 & 0.172 & {$[-0.589,0.089]$} \\
\hline \multicolumn{7}{|c|}{$\begin{array}{l}\text { Discriminatory Public } \\
\text { Policy Endorsement }\end{array}$} \\
\hline AIDS Target & -0.018 & 0.054 & {$[-0.148,0.074]$} & -0.301 & 0.292 & {$[-0.879,0.275]$} \\
\hline Gay Target & $-0.176^{*}$ & 0.066 & {$[-0.346,-0.075]$} & $-0.938^{*}$ & 0.235 & {$[-1.402,-0.473]$} \\
\hline \multicolumn{7}{|l|}{ Intention to Help } \\
\hline AIDS Target & $0.080^{*}$ & 0.050 & {$[0.004,0.214]$} & $0.631^{*}$ & 0.301 & {$[0.037,1.225]$} \\
\hline Gay Target & $0.156^{*}$ & 0.058 & {$[0.065 .0 .299]$} & $0.966^{*}$ & 0.282 & {$[0.409,1.523]$} \\
\hline
\end{tabular}

\section{Discussion}

The present study replicates and extends the findings from Study 1. Using a quasiexperimental methodology, we demonstrated that people's moral values, specifically the tradeoff between sanctity and care, explained their tendencies to deny rational minds to sexual outgroup members, and that relative denial of mind, in turn, predicted attitudes, explicit and automatic prejudice, as well as support for discriminatory public policies and interest in helping.

${ }^{5}$ Given the non-significant findings and the relatively low reliability of the AIDS-relevant policies (ending needle exchanges; mandating that people with AIDS register with the government, $\alpha=.48$ ) we conducted a follow up analysis examining each policy individually; however, the indirect and direct pathways were non-significant for both policy questions (indirect, $b \mathrm{~s}<.04$; direct $b \mathrm{~s}<.52, p \mathrm{~s}>.17$ ). 
Critical for our framework, people's tendency to deny minds to sexual outgroup members consistently mediated the relationship between moral values and prejudice. Aggregating across Studies 1 and 2, denial of mind was a significant mediator in 11 of 12 models (the overall nonsignificant model predicting AIDS policy preferences being the one exception). Additionally, we demonstrated in both Study 1 and 2 that sanctity-care and denial of mind account for unique variance in prejudicial attitudes and behaviors over-and-above the effects of political orientation or other moral values (Study 1). We again demonstrated theoretically predicted specificity in our findings. The sanctity-care tradeoff predicted a very narrow form of denial of mind - affecting only sexual outgroups (gay men; people with AIDS), while not affecting perceptions of other outgroups (e.g., African Americans). Further, the data suggest that the sanctity-care tradeoff uniquely predicts denial of mind and prejudice, whereas other moral values (i.e., fairness, authority, and loyalty) failed to predict any variables of interest.

Political orientation did remain a significant predictor of several behavioral outcomes ( 5 of 12 models) even when the sanctity-care tradeoff acted as a significant mediator of the effect. However, our theory does not dispute that people's politics are important determinants of moral values or their social behavior. Rather, we argue that moral values help explain the relationship between politics and a specific forms of prejudice. Thus, while we grant that politics influence attitudes, stereotypes, and behaviors toward sexual outgroups, we nevertheless emphasize that people's moral values play a unique and mediating role in explaining perceptions of mind and prejudice toward sexual outgroups.

It is worth noting that politics was not a significant predictor above and beyond morals and denial of mind for five of our six assessments of attitudes toward sexual outgroup targets. Not surprisingly, it was the public policy support and collective action intentions (i.e., helping), where politics remained a predictor above and beyond moral values and denial of mind. Whereas morals and denial of mind influenced people's attitudes and beliefs about sexual outgroups as well as their behavioral responses toward these groups, the influence of politics was localized to people's decisions about which policies to support and whether they intend on engaging in collective action.

The one exception to our pattern of findings was that moral values and denial of mind did not predict AIDS-relevant policy preferences. It is possible that people perceived these policies as less about people with AIDS and more about the role and size of government. Additionally, since the AIDS crisis in the U.S. and its accompanying policy debate peaked over 20 years ago, it is possible that current participants lack strong opinions about AIDS-related policies. In contrast, denial of mind was a key predictor of policies relevant to gay people (conversion therapy and national gay-marriage legislation), and denial of mind consistently mediated the impact of the sanctity-care tradeoff on support for anti-gay policies and prejudice.

Together Studies 1 and 2 demonstrate correlational support for our two key hypotheses: (1) prioritizing sanctity relative to care increases people's tendency to dehumanize and express prejudice towards sexual out-groups, and (2) the denial of a rational mind mediates the relationship between the sanctity-care tradeoff and expressions of prejudice and discrimination. However, both Studies rely on a single, self-report measure of people's moral values. Therefore in Study 3, we attempt to extend these findings using an alternative measure of people's moral values and testing the effect of sanctity-care tradeoffs on dehumanization and prejudice towards transgender targets. 


\section{Study 3}

Study 3 had two primary goals. First, we aimed to replicate our findings with an alternative measure of moral values, and second we wanted to extend our findings to an additional sexual outgroup target: transgender individuals. In this study we used a taboo-tradeoff measure of moral values. Taboo tradeoffs (Tetlock et al., 2000) are decisions where an individual gives up something sacred (e.g., one's moral values or soul) in exchange for something profane or common (e.g., money). We adopted a paradigm from Graham, et al. (2009, Study 3), in which participants are confronted with choices where they consider how much money they would require to perform a behavior that would violate a moral value. For example, people consider how much money would someone have to pay them to: "Stick a pin into the palm of a child you don't know." (Care)? or "Get a blood transfusion of 1 pint of disease-free, compatible blood from a convicted child molester." (Sanctity)?

Thus in Study 3 we attempt to replicate and extend our pattern of findings using an alternative measure of moral values. Additionally, in Study 3, we wanted to examine an additional sexual outgroup: transgender people. Past work demonstrates that people's attitudes towards transgender people are strongly associated with other sexual outgroups (e.g., gay men and lesbians); however, attitudes towards transgender people tend to be more negative than attitudes toward other sexual outgroups (Norton \& Herek, 2013). Moreover, recent research shows that transgender people are at increased risk for depression and anxiety disorders relative to cisgender individuals; perceived social stigma and lack peer support reinforces these problems (Bockting, Miner, Swinburne-Romine, Hamilton, \& Coleman, 2013), and interventions seeking to reduce discrimination towards transgender people have been largely unsuccessful (Case \& Stewart, 2013). Thus, in Study 3 we examined whether prejudice and discrimination towards transgender individuals is also explained via moral values and dehumanization.

\section{Methods}

\section{Participants}

We used the same a priori power analysis from Study 1 to determine our sample size $\left(\mathrm{G}^{*}\right.$ Power linear multiple regression; assumed $r^{2}=0.05$; power $\left.=0.95\right)$. The analysis revealed a required sample size of 249 participants; however, we elected to oversample and set our stopping rule at 300 participants. In total, we recruited 301 participants online using MTurk (mean age = 39.22 years, $S D=12.99)$. The majority of the sample identified as female $(n=165)$ and White $(n$ $=242)$, with smaller numbers identifying as Asian/Asian American $(n=20)$, African American $(n=15)$, Latin/Hispanic $(n=7)$, Native American $(n=2)$, or multiethnic $(n=14)$. Participants were moderately religious $(M=2.41, S D=1.49 ; 1=$ not at all religious; $5=$ very religious $)$ and politically moderate $(M=3.51, S D=1.75 ; 1=$ very liberal; $7=$ very conservative $)$.

\section{Procedure}

After consenting to participate, participants completed a behavioral measure of their moral values (moral tradeoffs, from Graham et al., 2009 Study 3). We presented participants with five different moral tradeoffs for each moral value: care $(\alpha=.80)$, fairness $(\alpha=.80)$, loyalty $(\alpha=.79)$, authority $(\alpha=.79)$, sanctity $(\alpha=.76)$. In each tradeoff participants considered how much money someone would have to pay them for them to violate a moral value (e.g., how much money would someone have to pay you to: "Make cruel remarks to an overweight person about his or her appearance." (Care)? or "Sign a piece of paper that says "I hereby sell my soul, after 
my death, to whoever has this piece of paper." (Sanctity)? Response options for each action were $\$ 0$ (I'd do it for free), $\$ 10, \$ 100, \$ 1,000, \$ 10,000, \$ 100,000$, a million dollars, and never for any amount of money.

Afterwards participants were presented with the two target persons: a transgender woman and White male. The description of the White target was identical to Studies 1 and 2. The description of the transgender woman read: "Sheila Radcliff is 32 years old and works at a department store. She was born male, but is transgender and identifies as female." As with all other target descriptions, the transgender target description was intentionally sparse in order to allow participants to fill in ambiguities with personally held beliefs.

For each target, participants responded to the same six-item dehumanization measure and the three-item prejudice measure $(\alpha=.84)$ used in the previous studies. The dehumanization questionnaire (Haslam et al., 2009) contained three items measuring denial of a rational mind $(\alpha$ $=.71)$ and three items measuring denial of basic human emotions $(\alpha=.69)$.

For the transgender target, we assessed explicit prejudice using the modified ATB $(\alpha$ $=.93)$. We also assessed implicit prejudice toward transgender individuals using the semantic differential scale $(\alpha=.97)$ measure used in Study 2. After the prejudice measures, participants responded to two public policy questions relevant to transgender people (favoring restrictive bathroom laws for transgendered people, favoring allowing transgender people to serve openly in the U.S. military [reverse scored]). These two items were strongly correlated $(r=.59, p<.001)$ and were combined into a single, hostile public policy item.

After completing the measures described above, participants self-reported their moral values using the MFQ (Graham et al., 2009): care $(\alpha=.77)$, fairness $(\alpha=.73)$, loyalty $(\alpha=.81)$, authority $(\alpha=.78)$, and sanctity $(\alpha=.88)$ moral values. Participants self-reported moral values within each domain significantly correlated with their responses to the moral tradeoffs for each of the moral domains: care $(r=.44, p<.001)$, fairness $(r=.30, p<.001)$, loyalty $(r=.41, p$ $<.001)$, authority $(r=.38, p<.001)$, sanctity $(r=.30, p<.001)$, and the sanctity-care tradeoff $(r$ $=.30, p<.001)$. The MFQ produced identical results to the moral taboo measure of moral values, and we report these findings in the Supplementary Analyses.

Lastly, participants responded to two measures assessing their willingness to engage in two pro-transgender behaviors (Anonymously donating money to a Trans-advocacy organization; Participating in a nationally-televised rally supporting Trans awareness) on a 1 (very unlikely) -7 (very likely). These two items were strongly correlated $(r=.82, p<.001)$ and were combined into a single pro-transgender behavioral intention measure.

\section{Results}

\section{Moral Tradeoffs}

Examining people's willingness to tradeoff moral values for money revealed that they were strongly hesitant to tradeoff either care $(M=6.31, S D=1.30)$ or sanctity values $(M=6.60$, $S D=1.28)$ for money, with average responses falling between requiring $\$ 100,000$ (6) and $\$ 1$ million (7) to violate either value. However, people were significantly more averse to trading off sanctity values compared to harm, $t(300)=4.95, p<.001, d=0.28,95 \% \mathrm{CI}[0.170,0.400]$. We created the sanctity-care tradeoff by subtracting participants' average willingness to commit care violations from their average willingness to commit sanctity violations (i.e., sanctity tradeoffs care tradeoffs). Thus, higher scores indicate comparatively stronger endorsement of sanctity relative to care. 


\section{Examining the Effects of Moral Values and Denial of Mind on Prejudice}

As in Study 1, we used Hayes' (2013) PROCESS macro (model 4) with 10,000 bootstrapped samples to test whether denial of mind mediated the relationship between the sanctity-care tradeoff and prejudicial attitudes, automatic and explicit prejudice, policy preferences, and pro-trans helping intentions (see Figure 4). Across all models, the sanctity-care tradeoff significantly predicted denial of mind for the transgender target, $b=0.156, p=.022$, $95 \%$ CI $[0.022,0.290]$. By contrast, the sanctity-care tradeoff did not predict denial of mind to the White target, $b=-0.075, p=.148,95 \%$ CI [-0.178, 0.027], and the mediation model for prejudice against the White target was not significant, indirect $b=-0.027,95 \%$ CI $[-0.070$, 0.010].

Attitudes toward the transgender target. Evaluating the mediation model showed that the sanctity-care tradeoff significantly predicted prejudicial attitudes, $b=0.273$, se $=.052,95 \%$ CI $[0.170,0.377]$. However, attitudes toward the transgender target were mediated by denial of mind, $b=0.503$, se $=.034,95 \%$ CI $[0.436,0.570]$, which significantly reduced the direct effect of sanctity-care on prejudicial attitudes, $b=0.195$, se $=.040,95 \% \mathrm{CI}[0.116,0.274]$, indicating evidence for partial mediation, overall indirect effect $b=0.079$, se $=.030,95 \% \mathrm{CI}[0.024$, $0.142]$.

Automatic prejudice. Similar effects emerged for automatic expressions of transgender prejudice. Initially, the sanctity-care tradeoff significantly predicted automatic prejudice, $b=$ $0.346, s e=.080,95 \%$ CI $[0.187,0.504]$. Including denial of mind in the model showed that it strongly predicted automatic prejudice, $b=0.790, s e=.051,95 \%$ CI $[0.690,0.891]$, and the direct effect of the sanctity-care tradeoff was reduced, $b=0.226$, se $=.060,95 \% \mathrm{CI}[0.107$, $0.345]$, indicating significant partial mediation, overall indirect effect $b=0.120, s e=.047,95 \%$ CI $[0.032,0.217]$.

Explicit prejudice. Explicit prejudice mirrored the effects above. Sanctity-care significantly predicted explicit prejudice, $b=0.476$, se $=.077,95 \% \mathrm{CI}[0.325,0.629]$. Simultaneously entering denial of mind in the model showed a strong effect, $b=0.767$, se $=.048,95 \% \mathrm{CI}[0.672,0.862]$, and the direct effect of the sanctity-care tradeoff was reduced, $b=$ $0.361, s e=.057,95 \% \mathrm{CI}[0.249,0.474]$, indicating significant partial mediation, overall indirect effect $b=0.115$, se $=.047,95 \%$ CI $[0.031,0.213]$.

Anti-transgender policy preferences. As in Study 2, we asked participants to give their opinions on two public-policy initiatives (restrictive bathroom laws, allowing transgender people to serve openly in the U.S. military). Analysis showed that sanctity-care significantly predicted participants' policy preferences, $b=0.459, s e=.101,95 \%$ CI $[0.260,0.658]$. Entering denial of mind into the model showed a strong predictive effect, $b=0.825$, se $=.071,95 \%$ CI $[0.684$, $0.965]$, and a reduction in the direct effect of sanctity-care, $b=0.335$, se $=.085,95 \%$ CI [0.168, $0.502]$, indicating significant partial mediation, overall indirect effect $b=0.124, s e=.049,95 \%$ CI $[0.032,0.228]$.

Pro-trans helping intentions. At the conclusion of the Study, we asked participants to report if they would be willing engage in two pro-transgender behaviors (Anonymously donating money to a Trans-advocacy organization; Participating in a nationally-televised rally supporting Trans awareness). Analysis showed that sanctity-care negatively predicted participants' willingness to help, $b=-0.520$, se $=.105,95 \% \mathrm{CI}[-0.727,-0.313]$. The full mediation model showed that denial of mind strongly predicted helping intentions, $b=-0.759$, se $=.078,95 \% \mathrm{CI}$ $[-0.912,-0.606]$, and the direct effect of sanctity-care was reduced, $b=-0.406$, se $=.092,95 \% \mathrm{CI}$ 
$[-0.588,-0.224]$, indicating significant partial mediation, overall indirect effect $b=-0.114$, se $=.045,95 \% \mathrm{CI}[-0.207,-0.029]$.

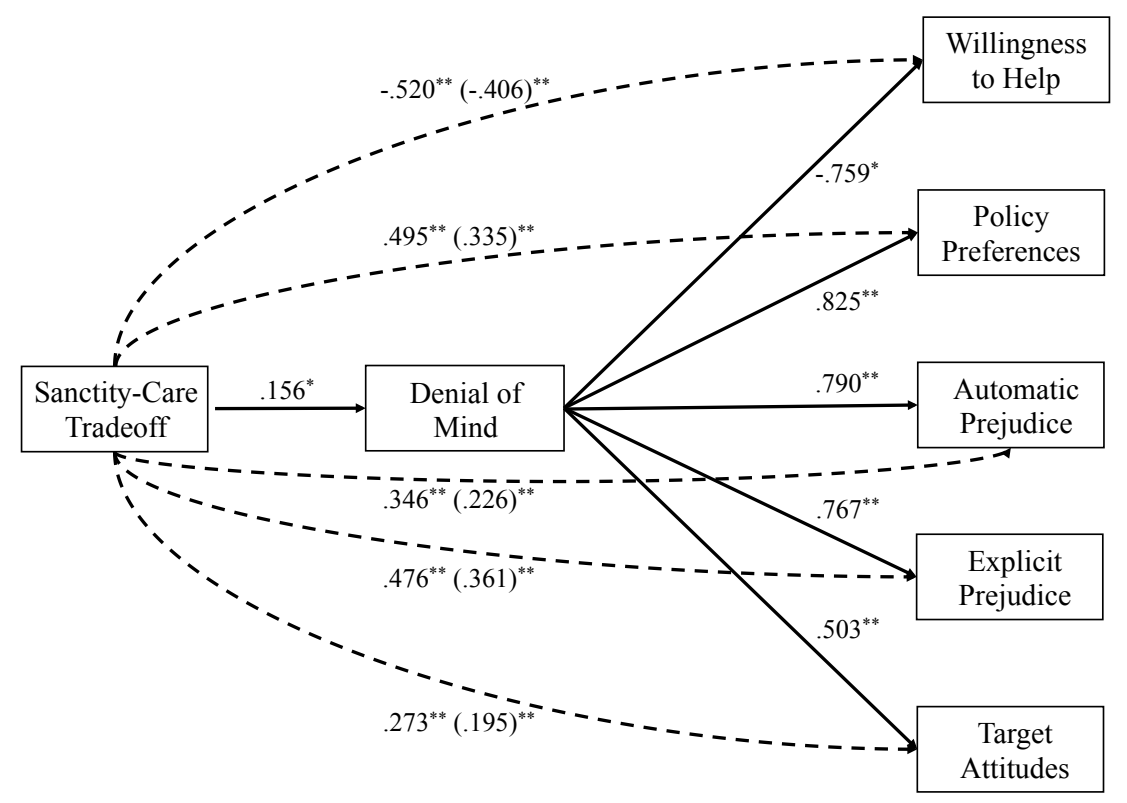

Figure 4. Unstandardized path coefficients. Relative denial of a rational mind mediated the relationship between moral values (sanctity-care tradeoff) and target attitudes, prejudice, discriminatory public policies, and pro-gay volunteerism. ${ }^{*}=p \leq .01,{ }^{* *}=p<.001$.

\section{Discussion}

The present study again replicated our core findings using a new measure of people's moral values - people's willingness to accept taboo offers to violate a moral value for money. As in our previous studies, we demonstrate that people who more strongly value sanctity relative to care are more likely to perceive transgender individuals as possessing a less rational mind. This in turn mediates the relationship between moral values and expression of prejudice towards individual transgender targets, as well as explicit and automatic prejudice directed towards transgender individuals, refusing help transgender people, and the endorsement of large-scale discriminatory public policies targeting transgender people.

Three studies now provide correlational evidence linking people's moral values, denial of mind, and expressions of prejudice and discrimination. Causal evidence for this conclusion, however, is still lacking. The goal of Study 4 was to provide this evidence by using a religious prime to increase the moralization of sanctity and thereby intensify denial of mind and prejudice.

\section{Study 4}

Using a naturalistic manipulation of religious concerns, Study 4 manipulated people's emphasis on sanctity values in a novel way. In this study, we solicited people in public places, asking them to participate in a short, one-page study. Key to our manipulation, we solicited responses either on Ash Wednesday (a Christian holiday associated with fasting, purification, and devotion to God) or in the same locations on Wednesday three weeks later (a non-religious day). We hypothesized that people surveyed on Ash Wednesday would report greater sanctity concerns than people surveyed on the non-religious day. In contrast, we predicted care concerns 
would be unaffected by the date since Ash Wednesday has no special association with care. We predicted that this relative focus on sanctity versus care would lead to greater denial of mind and, thus, more negative attitudes and behaviors toward sexual outgroups. Additionally, in the present study, we used a new sexual outgroup member: a female prostitute. We suspected that because sanctity is strongly associated with restricting sexual behavior, female prostitutes would likely be perceived as violating norms of sanctity.

\section{Method}

\section{Participants and Procedure}

We assumed a moderate effect of our manipulation $(d=0.4$; Power $=0.8)$, which indicated a required sample size of 100 participants per condition. Our goal was therefore to collect at least 100 participants on Ash Wednesday and to match that sample on our control day. In total, we recruited 236 participants (Ash Wednesday $n=112$; Control $n=124$ ) on and around the campus of a large Southeastern State University. The majority of participants were female $(n$ $=158)$, and the average age in the sample was 20.6 years $(S D=1.91)$. Because of the short format of the study, we did not collect any other demographic information. Other studies on campus, however, revealed that students were moderately religious $(M=2.31, S D=2.17)$, (Scale: 0 Not at all - 5 Very Religious), which led us to believe they might be affected by the Ash Wednesday manipulation.

Research assistants who were blind to condition and the study's hypotheses approached participants in public places on the University campus. After providing verbal consent, participants completed a one-page (front and back) survey. On the front of survey participants responded to two questions from the care subscale of the MFQ $(r=.25, p<.001$, "One of the worst things a person could do is hurt an animal." "When deciding if something is right or wrong it matters to me whether or not someone suffered emotionally.") and two questions from the sanctity subscale $(r=.29, p<.001$, "When deciding if something is right or wrong it matters to me whether or not someone acted in a way that God would approve of." "People should not do things that are disgusting, even if no one is harmed."). Responses were on a 0 (Strongly Disagree) - 5 (Strongly Agree) scale.

On the back of the survey, participants were presented with the following description of a woman who decided to work as a prostitute: "Sheila Radcliff is 32 years old. She works as a waitress at a diner. Recently she decided to start working as a prostitute, sleeping with men in exchange for money." Afterwards participants responded to two questions measuring denial of a rational mind ("Sheila is rational and logical."[reverse scored] and "Sheila lacks self-restraint.") and two items measuring denial of basic human emotions ("Sheila is rigid and cold." "Sheila is warm towards others." [reverse scored]) using a 0 not at all -6 extremely Likert scale. Finally, participants completed a one question measure of prejudice toward the target ("If given the chance, I would stand up for Sheila.") on a 0 definitely "no" to 4 definitely "yes" Likert scale, and they responded to one public policy question about decriminalizing prostitution (scale: 0 Totally opposed -6 Totally in favor). 


\section{Results}

\section{Manipulation Check}

We first tested whether our naturalistic manipulation of religious concern differentially affected care and sanctity values. As predicted, participants in our two conditions significantly differed on sanctity concerns, $t(234)=2.89, p=.004, d=0.38,95 \%$ CI $[0.12,0.64]$. Ash Wednesday participants reported significantly higher sanctity concerns $(M=2.98, S D=1.18)$ compared to control participants $(M=2.53, S D=1.19)$. By contrast, as predicted, the manipulation did not affect concerns about care $t(234)=1.18, p=.239, d=0.16,95 \% \mathrm{CI}[-0.10$, 0.41]. People in the Ash Wednesday condition expressed slightly higher concerns about care $(M$ $=3.74, S D=0.97)$ compared to control $(M=3.59, S D=0.96)$, but those differences were not significant.

\section{Strengthening Sanctity Concerns Intensifies Denial of Mind and Prejudice}

The religious prime significantly affected participants' perceptions of the prostitute's mind. Participants in the sanctity-induction condition (i.e., those surveyed on Ash Wednesday) dehumanized $(M=3.70, S D=0.95)$ the prostitute target more than control participants $(M=3.07$, $S D=1.21), t(234)=4.41, p<.001, d=0.57,95 \%$ CI [0.31, 0.83]. Further, participants in the sanctity condition $(M=2.46, S D=1.09)$ reported less positive attitudes towards the prostitute relative to participants in the control condition $(M=2.85, S D=1.00), t(234)=2.82, p=.005, d=$ $0.37,95 \%$ CI $[0.11,0.62]$. In addition, participants in the sanctity condition also reported decreased willingness to decriminalize prostitution $(M=2.35, S D=1.89)$ compared to participants in the control condition $(M=3.21, S D=1.90), t(234)=3.48, p=.001, d=0.45$, $95 \%$ CI $[0.19,0.71]$.

We next tested whether the sanctity-care tradeoff and denial of mind mediated the effect of the religious prime condition on outgroup negativity: expressing prejudicial attitudes and opposition to a compassionate public policy (Hayes, 2013, model 6, two-stage mediation, 10,000 bootstrapped samples). Consistent with predictions, this two-stage mediation model was significant for attitudes toward the target, indirect $b=0.010, s e=.007,95 \%$ CI $[0.002,0.034]$, and decriminalizing prostitution, indirect $b=0.016$, se $=.011,95 \% \mathrm{CI}[0.002,0.055]$. After accounting for the indirect effect, the direct effects of the religious prime became nonsignificant for attitudes toward the target, direct $b=0.226$, se $=.139,95 \%$ CI [-0.049, 0.501], and endorsing decriminalizing prostitution, direct $b=0.429$, se $=.235,95 \%$ CI [-0.030, 0.892].

\section{Discussion}

Study 4 provided empirical evidence for the link between moral values, denial of mind, and prejudice. Using a naturalistic manipulation of religious concern, we assessed people's moral values at a time we anticipated their sanctity concerns would be heightened (i.e., Ash Wednesday) versus not. This manipulation increased people's endorsement of sanctity values, while leaving concerns about care unaltered. The heightened endorsement of sanctity increased denial of mind of the sexual outgroup member and caused corresponding increases in expressions of prejudice and opposition to decriminalizing prostitution. Thus, intensifying people's attention to sanctity (holding care constant) appears to result in the motivated denial of mind to sexual outgroup targets and the licensure of prejudice and discrimination. 


\section{Study 5}

Whereas Study 4 provided evidence that priming sanctity can intensify biases against sexual outgroups, in Study 5 we tested the opposite possibility. In this Study, we examined whether manipulating sensitivity to care principles reduces denial of mind and prejudice toward sexual outgroup members. Further, we wanted to return to examining attitudes and behaviors towards gay men and transgender people. Thus, in this study we explored whether manipulating people's moral beliefs about care might effectively improve their attitudes and behaviors towards gay and transgender people.

\section{Method}

\section{Participants}

Previously published work on in-lab inductions of moral values have generally obtained strong effects (e.g., $\mathrm{d}<.7$; Schnall, Haidt, Clore, \& Jordan, 2008) and online studies with moral value inductions obtain similar findings (e.g., $\mathrm{d}<.45$; Waytz et al., 2013 Study 2a). Thus, for our power analysis $\left(\mathrm{G}^{*}\right.$ Power, independent samples t-test, one tailed) we assumed a moderate effect for the care induction $(d=0.6)$ and relaxed our desired power level $(0.8)$, yielding a required sample size of 36 participants per condition.

In total, we recruited 80 U.S. participants using Amazon Mechanical Turk. The average age in the sample was 36.7 years $(S D=10.6)$, and we obtained equal numbers of men $(n=41)$ and women $(n=39)$ in the sample. The majority of participants identified as White $(n=61)$, with smaller numbers of participants identifying as African American $(n=10)$, Asian $(n=7)$, or Latino $(n=2)$. The sample was politically moderate, leaning slightly liberal $(M=3.11, S D=$ 1.57) based on a 1 (very liberal) - 7 (very conservative) scale, and participants reported being less religious $(M=1.33, S D=1.32)$ on a 1 (not at all religious) - 5 (very religious) scale.

\section{Procedure}

After participants consented to participate in the study and completed a brief speakervolume test, they were randomly assigned to either the care-induction or control condition. In both conditions participants listened to a two-minute news audio clip that reviewed a recent news story; however, the clips were selected either to highlight concerns about care or to be morally neutral. In the control condition the audio clip described the UK vote to leave the European Union (a report lacking any particular moral value for US participants). In the care-induction condition the audio clip discussed the importance of safe spaces for communities of color. We chose this audio clip because although it emphasizes concerns about care, the group the clip references is a non-sexual outgroup.

Immediately following the audio clip, participants rated their endorsement of care $(\alpha$ $=.76)$, fairness $(\alpha=.75)$, loyalty $(\alpha=.79)$, authority $(\alpha=.74)$, and sanctity $(\alpha=.88)$ using the MFQ (Graham et al., 2009) and made judgments of three targets: a transgender woman, a gay man, and a White man. Descriptions of the gay, transgender and White targets were identical to those used previously. The order of the gay and transgender target was randomized; the White target was always presented last.

After reading each target description participants completed the same six-item dehumanization from the previous Studies. The measure contained three questions measuring denial of a rational mind $(\alpha=.82)$ and three items measuring denial of basic human emotions $(\alpha$ $=.92$ ). Additionally, for both targets, participants completed the three-item measure of attitudes 
toward the target (identical to previous studies, $\left.\alpha_{\text {gay }}=.87 \alpha_{\text {trans }}=.88\right)$, and a modified ATB $\left(\alpha_{g a y}\right.$ $\left.=.93 \alpha_{\text {trans }}=.91\right)$ and semantic differential scale $\left(\alpha_{\text {gay }}=.97 \alpha_{\text {trans }}=.98\right)$.

Participants next rated three public policy proposals; two pertaining to gay targets (favoring gay conversion therapy, favoring national gay-marriage legislation [reverse scored], $r$ $=.60, p<.001$ ), and one transgender-relevant policy (favoring restrictive bathroom laws for transgendered people) on a 1 (not at all in favor) - 7 (very much in favor) scale. Finally, participants completed a memory check question probing whether they recalled the audio clip content (all participants answered this question correctly), a short demographic form, and the debriefing form.

\section{Results}

\section{Manipulation Check}

An independent-samples t-test confirmed that the audio clip manipulation significantly affected participants' endorsement of care values. Participants who listened to the audio clip about safe spaces for African American communities espoused stronger endorsement of the care foundation $(M=5.17, S D=0.66)$ compared to control $(M=4.62, S D=0.74), t(78)=3.50, p$ $=.001, d=0.78,95 \% \mathrm{CI}[0.33,1.24]$. There was also a marginally significant effect of the manipulation on sanctity concerns, $t(78)=1.77, p=.080, d=0.40,95 \%$ CI $[-0.05,0.84]$. Participants in the care condition $(M=2.96, S D=1.21)$ had a slightly reduced concern for sanctity relative to control $(M=3.47, S D=1.35)$. As in previous studies, we subtracted individual's sanctity scores from care to create a sanctity-care tradeoff score for each participant and found that participants in the care condition had a weaker tendency to value sanctity relative to care $(M=-2.21, S D=1.32)$ than participants in the control condition $(M=-1.15, S D=1.43)$, $t(78)=3.44, p=.001, d=0.77,95 \%$ CI $[0.31,1.22]$.

\section{Strengthening Care Values Mollifies Denial of Mind and Prejudice}

The care manipulation significantly affected participants' perceptions of the gay and transgendered targets' minds (see Table 2). ${ }^{6}$ Participants in the care-induction condition dehumanized gay and transgender targets less than participants in the control condition, $t_{\text {gay }}(78)$ $=2.53, p=.013, d=0.57,95 \% \mathrm{CI}[0.12,1.01] ; t_{\text {trans }}(78)=2.56, p=.027, d=0.58,95 \% \mathrm{CI}$ $[0.12,1.02]$. Additionally, the care manipulation reduced explicit prejudice towards gay and transgender targets, $t_{\text {gay }}(78)=2.95, p=.004, d=0.67,95 \% \mathrm{CI}[0.21,1.11] ; t_{\text {trans }}(78)=2.28, p$ $=.026, d=0.52,95 \% \mathrm{CI}[0.06,0.95]$, and it reduced acceptance for discriminatory public policies for both targets, $t_{\text {gay }}(78)=2.34, p=.022, d=0.53,95 \% \mathrm{CI}[0.08,0.97] ; t_{\text {trans }}(78)=2.79$, $p=.007, d=0.63,95 \%$ CI $[0.17,1.07]$. The care manipulation, however, did not significantly affect attitudes toward the targets, $t_{\text {gay }}(78)=1.53, p=.13, d=0.35,95 \% \mathrm{CI}[-0.10,0.78]$; $t_{\text {trans }}(78)=1.48, p=.14, d=0.34,95 \%$ CI [-0.11, 0.77] or automatic prejudice, $t_{\text {gay }}(78)=1.00, p$ $=.32, d=0.23,95 \% \mathrm{CI}[-0.22,0.66] ; t_{\text {trans }}(78)=0.80, p=.43, d=0.18,95 \% \mathrm{CI}[-0.26,0.62]$.

\footnotetext{
${ }^{6}$ By contrast, the manipulation had no effect on perceptions of the White target's mind or on prejudice towards the White target $t \mathrm{~s}<1.4, p \mathrm{~s}>.19$.
} 
Table 2. Descriptive Statistics for Denial of a Rational Mind, Target Attitudes, Prejudice, and Acceptance of Discriminatory Public Policies Toward Transgender and Gay Targets.

\begin{tabular}{|c|c|c|c|c|}
\hline & \multicolumn{2}{|c|}{ Transgender Target } & \multicolumn{2}{|c|}{ Gay Target } \\
\hline & Mean & $S D$ & Mean & $S D$ \\
\hline \multicolumn{5}{|c|}{ Denial of a Rational Mind } \\
\hline Control & 3.45 & 1.11 & 3.23 & 0.89 \\
\hline Care Induction & 2.90 & 1.05 & 2.72 & 0.92 \\
\hline \multicolumn{5}{|l|}{ Target Attitudes } \\
\hline Control & 3.43 & 1.01 & 3.53 & 0.97 \\
\hline Care Induction & 3.74 & 0.85 & 3.83 & 0.72 \\
\hline \multicolumn{5}{|l|}{ Explicit Prejudice } \\
\hline Control & 3.34 & 0.74 & 3.16 & 0.59 \\
\hline Care Induction & 3.00 & 0.61 & 2.82 & 0.42 \\
\hline \multicolumn{5}{|l|}{ Automatic Prejudice } \\
\hline Control & 2.80 & 1.51 & 2.52 & 1.23 \\
\hline Care Induction & 2.56 & 1.12 & 2.27 & 0.98 \\
\hline \multicolumn{5}{|c|}{ Public Policy Endorsement } \\
\hline Control & 3.38 & 2.07 & 2.79 & 1.87 \\
\hline Care Induction & 2.15 & 1.85 & 2.00 & 1.01 \\
\hline
\end{tabular}

Note: Means that do not share a subscript are significantly different from one another, $p \leq .01$

Given the patterns of identical findings for the two targets, and strong correlations between the gay and transgender targets denial of mind $(r=.70, p<.001)$; positive attitudes $(r$ $=.91, p<.001)$, explicit prejudice, $(r=.81, p<.001)$, automatic prejudice $(r=.83, p<.001)$, and policy preferences $(r=.59, p<.001)$. We collapsed across target type when testing our mediation models. We first tested whether moral values and denial of mind mediated the relationship between the care manipulation and the two dependent measures (explicit prejudice and public policy endorsement) affected by the care manipulation (Hayes, 2013, model 6, twostage mediation, 10,000 bootstrapped samples). The model showed that the care manipulation significantly predicted the sanctity-care tradeoff, $b=-1.058, p<.001,95 \%$ CI $[-1.671,-0.104]$, and the sanctity-care tradeoff predicted denial of mind, $b=0.171, p=.022,95 \%$ CI [0.026, 0.316]. Further, the full two-stage mediation model (condition $\rightarrow$ sanctity-care tradeoff $\rightarrow$ denial of mind $\rightarrow$ behavioral outcome) was significant for both explicit prejudice (indirect $b=-0.038$, $s e=.028,95 \% \mathrm{CI}[-0.125,-0.006])$ and endorsement of discriminatory public policies, indirect $b$ $=-0.042, s e=.030,95 \%$ CI $[-0.136,-0.006]$. Similarly, even though the direct effect of the care manipulation was not significant for positive attitudes or automatic prejudice, the indirect pathway through moral values and denial of mind was significant in both cases. Moral values and denial of mind mediated the relationship between the care induction and positive attitudes toward the targets (indirect $b=0.101, s e=.064,95 \% \mathrm{CI}[0.017,0.281]$ ), and automatic prejudice, indirect $b=-0.164, s e=.10,95 \%$ CI [-0.448, -0.026]. 


\section{Model Comparison}

Finally, we compared our theoretically derived model (condition $\rightarrow$ sanctity-care tradeoff $\rightarrow$ denial of mind $\rightarrow$ attitudes and behaviors) with an alternative model. According to this alternative model, dislike for sexual outgroup members is what motivates people's moral values, and ultimately, their ascriptions of mind. Thus, within the context of this experiment, the alternative model predicts that the care induction should reduce participants' dislike of the targets, and thereby shift moral values, and finally, denial of mind (i.e., condition $\rightarrow$ attitudes $\rightarrow$ sanctity-care tradeoff $\rightarrow$ denial of mind). We tested this model (Hayes, 2013, model 6, twostage mediation, 10,000 bootstrapped samples), but found that the mediation model was not significant, indirect $b=-0.002, s e=.018,95 \%$ CI [-0.050, 0.028]). By contrast, our predicted model (as noted above) demonstrated that moral values and denial of mind were significant mediators for attitudes toward the targets, indirect $b=0.101$, se $=.064,95 \%$ CI $[0.017,0.281]$.

\section{Discussion}

Study 5 demonstrated that people's tendency to deny minds and discriminate against sexual outgroups can be ameliorated by increasing people's sensitivity to care principles, providing further evidence for the link between moral values, denial of mind, and prejudice. In conjunction with Study 4, these studies show that influencing either side of the sanctity-care tradeoff affects dehumanization and prejudice toward sexual outgroups. Heightening sanctity concerns intensifies negative outcomes, and emphasizing care values reduces them. Additionally, Study 5 afforded an opportunity to test our theoretically derived model against an alternative model positing that dislike for sexual outgroups explains our effects. Comparing these models revealed further support for our predictions and scant evidence for the alternative view. Lastly, Study 5 revealed a new potential method for combatting prejudice against sexual outgroups: focusing people on the importance of the moral value of care.

We hasten to add, that given the intuitive nature of morality (Haidt, 2001, 2008), changing people's moral values in the long-term may be difficult and other, more targeted interventions - for example, attempting to increase people's understanding of other's capacity for rational thinking - may be more effective for improving people's perceptions and behavior toward specific targets in the short-term. Indeed, existing research demonstrates substantial promise for such interventions (e.g., Costello \& Hodson, 2010; Tam et al., 2007; Vezzali, Capozza, Stathi, \& Giovannini, 2012). Nevertheless, we argue that intervening on moral values is promising because the breadth of its potential effects. In five Studies we demonstrate moral values explain prejudicial attitudes and behaviors for a wide range or targets, and thus, changing these moral values would possibly address all of these concerns at once rather than being target specific.

\section{General Discussion}

Five studies examined the relationship between moral values, denial of mind, and prejudice toward sexual outgroup members. We proposed a motivational framework whereby preferentially endorsing sanctity values over care biases perceptions sexual outgroup members' mind, and this tendency to dehumanize, in turn, legitimizes expressions of prejudice and discrimination toward these groups. Our studies confirmed this framework. People's endorsement of sanctity and care values consistently influenced their tendency to deny minds to gay men, people with AIDS, prostitutes, and transgender people. Further, this relative denial of 
mind predicted a host of behavioral outcomes including holding prejudicial attitudes (Studies 15), expressing explicit and automatic prejudice (Studies 2, 3, and 5), refusing to help (Studies 23 ), and increasing acceptance of discriminatory public policies (Studies 2-5).

These studies highlight denial of mind as an important mechanism undergirding prejudice. Across our five studies, we consistently found that denial of mind mediated the relationship between the sanctity-care tradeoff and negative behavioral outcomes. Whereas our studies are the first to demonstrate this effect in the context of morality, the finding broadly complements past work on racial prejudice showing that implicit dehumanization of Black people predicts increased tolerance for aggression toward Black people (Goff et al., 2008, 2014) and that the dehumanization of women leads to greater acceptance of sexual harassment and rape of women (Rudman \& Mescher, 2012). Thus, our studies support and extend the important impact of dehumanization. Our work further offers an important extension of prior research by demonstrating that a person's moral values can be an important antecedent to their tendency to dehumanize specific individuals. These findings are also broadly consistent with past research demonstrating that moral valence can affect how people make judgments about the content of other's minds (e.g., intentions, reasons, and knowledge), but ours is the first study to show evidence that moral inferences can affect people's beliefs about who has a (fully-human) mind at all.

Moreover, our data highlight important boundary conditions for the effect of moral values. The sanctity-care tradeoff did not affect perceptions of majority group members (i.e., White men, Studies 1-2, 5), nor did it affect perceptions of other marginalized, but non-sexual outgroups (e.g., obese people African Americans, Studies 1-2). Instead, the effect of the sanctitycare tradeoff on denial of mind and prejudice was specific. It affected only judgments of groups typically perceived as violating norms of moral sanctity: gay men, people with AIDS, prostitutes, and transgender people.

Lastly, the present studies demonstrate that the sanctity-care tradeoff and denial of mind account for unique variance in prejudicial attitudes and behaviors over-and-above the effects of one's political identity. Studies 1-3 suggest that sanctity-care and denial of mind are consistent predictors of prejudice after controlling for political orientation. Moreover Studies 2 and 3, reveal that people's moral values help to explain the link between political orientation and expression of prejudice toward sexual outgroups. Thus, our research extends previous theorizing about the relationship between politics and culture war issues by more clearly specifying the nature of the relationship. People's political identities influence the constellation of moral values they identify as important, and these moral values inform how they perceive the minds of others. The differential prioritization of sanctity versus care (by conservatives) motivates a dehumanizing view of sexual outgroup's minds, which in term validates prejudice.

\section{Theoretical extensions}

These studies identify an important benefit of studying moral values in conjunction with prejudice. Previous research suggests that morality defines how people perceive themselves (Strohminger \& Nichols, 2015), and our data show that it also importantly influences how people perceive others. Morality defines who is perceived as belonging, possessing a mind, and guaranteed rights, and who is excluded, mindless, and allowed to be hurt or neglected.

Our studies suggest that people's moral values can be (at least temporarily) altered and that highlighting certain moral values or downplaying others be an effective method for combatting prejudice. Emphasizing care decreased prejudicial attitudes, reduced expression of 
prejudice, and weakened acceptance of discriminatory public policies toward various sexual outgroups. These findings are consistent with research demonstrating that manipulating moral emotions can intensify disapproval of moral taboos (Buckels \& Trapnell, 2013; Cunningham, Forestell, \& Dickter, 2013; Horberg, Oveis, Keltner, \& Cohen, 2009; Inbar, Pizarro, \& Bloom, 2012). However, our studies go farther by targeting moral values themselves, rather than their associated moral emotions.

Our work also provides evidence that people's moral values affect prejudice by influencing its underlying causes, namely changing the way people perceive the minds of outgroup members. Consistent with previous research, we show that to the extent an agent is viewed as lacking a fully-human, rational mind, harming that agent is viewed as more permissible (Bastian et al., 2013, 2011, 2012; Haslam, 2006). Further, these findings highlight the fundamentally social nature of morality and moral judgment (Malle, Guglielmo, \& Monroe, 2012, 2014; Rai \& Fiske, 2011). Morality — and in particular moral values — shape the way people perceive the world and other's minds. And, as a result, it can have important downstream social consequences for people's attitudes, support of public policies, and eagerness to work to ensure or restrict rights and freedoms.

\section{Open Questions and Future Directions}

We focused our investigation on two particular moral values (care and sanctity) and their effects on perceptions and behaviors toward sexual outgroups. However, there remain many exciting questions for future exploration. One question raised by these data is whether tradeoffs between other moral values would predict prejudice towards other groups. We suspect so. Recent studies have demonstrated that heightened valuing of binding foundations (relative to individuating foundations) increased victim-blaming in cases of sexual assault (Niemi \& Young, 2016). Further, recent U.S. political movements on both the Right and the Left emphasize tradeoffs between moral values as part of their ethos. For example, messaging on the political Left emphasizes the need to prioritize fairness over other moral values, especially in the context of the so-called "one-percenters" unfairly benefitting at the expense of others. Thus, one might expect that people who strongly value fairness relative to care, might view members of groups perceived to violate norms of fairness (e.g., corporate CEOs) as less human than others, which could increase willingness to harm or penalize members of these groups.

Similarly, on the political Right, recent patterns of Nationalistic rhetoric emphasize the moralization of in-group loyalty (e.g., "America First") over other moral priorities (e.g., care for refugees). A straightforward prediction from these observations is that people who prioritize ingroup loyalty over care or fairness may be more likely to dehumanize and express prejudice towards members of groups that are perceived as threatening the cohesion of the ingroup (e.g., minority members, protesters, or immigrants). Thus, while the present studies focused on the tradeoff between the moral values of sanctity and care, we believe that the impact of moral values on denial of mind and prejudice expands beyond the values and groups examined here.

A second question for future research pertains to the persistence of these effects over time. Studies 4 and 5 examined the implications of temporarily changing people's moral values as a means for influencing denial of mind and prejudice. Changing people's moral values in the long-term may be difficult (and possibly morally questionable). However, it may be possible to change the implications of people's moral values for their evaluations of outgroups. For example, by decreasing the perception that sexual outgroups are impure (e.g., highlight the emotional bond between gay lovers as opposed to the sexual behavior), it may be possible to 
change the tendency to view sexual outgroups as moral outgroups. However, given the intuitive nature of morality (Haidt, 2001, 2008), changing such associations may prove difficult and require repeated pairings of new associations (e.g., "love is love").

An additional, important implication of mitigating people's tendencies to dehumanize sexual outgroups and their members is that it may increase the tendency to empathize with and take the perspective of these people. Taking the perspective of outgroup members can be an effective tool for decreasing prejudice and discrimination (Batson et al., 1997; Galinsky \& Moskowitz, 2000). Further, a lack of outgroup empathy may interfere with people reaping the full benefits of intergroup contact. Intergroup contact is well-established as one of the most consistently effective routes to decreasing prejudice (e.g., Allport, 1954; Pettigrew \& Tropp, 2006). However, one of the key mechanisms through which outgroup contact is effective in reducing prejudice is via empathy and perspective taking (e.g., Pettigrew \& Tropp, 2008). To the extent that moral outgroup members are perceived as not having human minds, it is unlikely that people will empathize with or perceive that they have the same perspective as these outgroup individuals, which could reduce the efficacy of potential routes to prejudice reduction.

\section{Conclusions}

Moral values have the power to do great good. They can cultivate cooperation, strengthen communities, and elicit empathy and helping for those in need. And yet, the present work highlights a dark side of moral values. Moral values and mind perception are fundamental features for explaining prejudice toward sexual outgroups. Prioritizing sanctity over care motivate dehumanization, which in turn legitimizes people's willingness to express prejudice, refuse help, and support harmful public policies toward individuals branded as violating deeply held standards for sanctity. Despite these negative linkages, our studies suggest reasons for optimism. In medicine, the first step to curing any disease is to understand its etiology. Similarly, we hope that illuminating the moral roots of sexual outgroup prejudice may spur additional work to combat it.

Authors Note: We wish to thank William Jimenez-Leal, Gordon Ingram, and the Florida State University social psychology graduate students for their helpful comments on this work. Parts of this research (Studies 1-2 and 4-5) were presented at the Annual meeting for Philosophy and Psychology (SPP) 2017. 


\section{References}

Allport, G. W. (1954). The nature of prejudice. Cambridge, MA: Perseus Books.

Bastian, B., Denson, T. F., \& Haslam, N. (2013). The roles of dehumanization and moral outrage in retributive justice. PLoS ONE, 8, e61842. doi:10.1371/journal.pone.0061842

Bastian, B., Laham, S. M., Wilson, S., Haslam, N., \& Koval, P. (2011). Blaming, praising, and protecting our humanity: The implications of everyday dehumanization for judgments of moral status. British Journal of Social Psychology, 50, 469-483. doi:10.1348/014466610X521383

Bastian, B., Loughnan, S., Haslam, N., \& Radke, H. R. M. (2012). Don’t Mind Meat? The Denial of Mind to Animals Used for Human Consumption. Personality and Social Psychology Bulletin, 38, 247-256. doi:10.1177/0146167211424291

Batson, C. D., Polycarpou, M. P., Harmon-Jones, E., Imhoff, H. J., Mitchener, E. C., Bednar, L. L., Klein, T. R., et al. (1997). Empathy and attitudes: Can feeling for a member of a stigmatized group improve feelings toward the group? Journal of Personality and Social Psychology, 72, 105-118. doi:10.1037/0022-3514.72.1.105

Beebe, J. R., \& Buckwalter, W. (2010). The epistemic side-effect effect. Mind and Language, 25, 474-498. doi:10.1111/j.1468-0017.2010.01398.x

Bockting, W. O., Miner, M. H., Swinburne-Romine, R. E., Hamilton, A., \& Coleman, E. (2013). Stigma, mental health, and resilience in an online sample of the US transgender population. American Journal of Public Health, 103, 943-951.

Brigham, J. C. (1993). College Students' Racial Attitudes. Journal of Applied Social Psychology, 23, 1933-1967. doi:10.1111/j.1559-1816.1993.tb01074.x

Buckels, E. E., \& Trapnell, P. D. (2013). Disgust Facilitates Outgroup Dehumanization. Group Processes \& Intergroup Relations, 1368430212471738. doi:10.1177/1368430212471738

Case, K. A., \& Stewart, B. (2013). Intervention effectiveness in reducing prejudice against transsexuals. Journal of LGBT Youth, 10, 140-158.

Cikara, M., Eberhardt, J. L., \& Fiske, S. T. (2011). From agents to objects: Sexist attitudes and neural responses to sexualized targets. Journal of Cognitive Neuroscience, 23, 540-551. doi:10.1162/jocn.2010.21497

Costello, K., \& Hodson, G. (2010). Exploring the roots of dehumanization: The role of animalhuman similarity in promoting immigrant humanization. Group Processes \& Intergroup Relations, 13, 3-22. doi:10.1177/1368430209347725

Cova, F., Lantian, A., \& Boudesseul, J. (2016). Can the Knobe Effect Be Explained Away? Methodological Controversies in the Study of the Relationship Between Intentionality and Morality. Personality and Social Psychology Bulletin, 42, 1295-1308. doi:10.1177/0146167216656356

Cunningham, E., Forestell, C. A., \& Dickter, C. L. (2013). Induced disgust affects implicit and explicit responses toward gay men and lesbians. European Journal of Social Psychology, 43, 362-369.

Cushman, F., Gray, K., Gaffey, A., \& Mendes, W. B. (2012). Simulating murder: The aversion to harmful action. Emotion, 12, 2-7. doi:10.1037/a0025071

Dungan, J., Waytz, A., \& Young, L. (2014). Corruption in the Context of Moral Trade-offs. Journal of Interdisciplinary Economics, 26, 97-118. doi:10.1177/0260107914540832

Dungan, J., \& Young, L. (2015). Understanding the Adaptive Functions of Morality from a Cognitive Psychological Perspective. Emerging Trends in the Social and Behavioral Sciences. John Wiley \& Sons, Inc. 
Galinsky, A. D., \& Moskowitz, G. B. (2000). Perspective-taking: Decreasing stereotype expression, stereotype accessibility, and in-group favoritism. Journal of Personality and Social Psychology, 78, 708-724. doi:10.1037/0022-3514.78.4.708

Gilligan, C. (1982). In a different voice: Psychological theory and women's development. Cambridge, MA: Harvard University Press.

Goff, P. A., Eberhardt, J. L., Williams, M. J., \& Jackson, M. C. (2008). Not yet human: implicit knowledge, historical dehumanization, and contemporary consequences. Journal of personality and social psychology, 94, 292.

Goff, P. A., Jackson, M. C., Di Leone, B. A. L., Culotta, C. M., \& DiTomasso, N. A. (2014). The essence of innocence: Consequences of dehumanizing Black children. Journal of personality and social psychology, 106, 526.

Goldin, G., \& Darlow, A. (2013). TurkGate. Version 0.4.0. Available from http://gideongoldin.github.com/TurkGate/.

Graham, J., Haidt, J., \& Nosek, B. A. (2009). Liberals and conservatives rely on different sets of moral foundations. Journal of Personality and Social Psychology, 96, 1029-1046. doi:10.1037/a0015141

Graham, J., Nosek, B. A., Haidt, J., Iyer, R., Koleva, S., \& Ditto, P. H. (2011). Mapping the moral domain. Journal of Personality and Social Psychology, 101, 366-385. doi:10.1037/a0021847

Gray, H. M., Gray, K., \& Wegner, D. M. (2007). Dimensions of mind perception. Science, 315 , 619-619. doi:10.1126/science.1134475

Gray, K., Young, L., \& Waytz, A. (2012). Mind perception is the essence of morality. Psychological Inquiry, 23, 101-124. doi:10.1080/1047840X.2012.651387

Haidt, J. (2001). The emotional dog and its rational tail: A social intuitionist approach to moral judgment. Psychological Review, 108, 814-834. doi:10.1037/0033-295X.108.4.814

Haidt, J. (2008). Morality. Perspectives on Psychological Science, 3, 65-72.

Haidt, J., \& Graham, J. (2007). When Morality Opposes Justice: Conservatives Have Moral Intuitions that Liberals may not Recognize. Social Justice Research, 20, 98-116. doi:10.1007/s11211-007-0034-Z

Haidt, J., \& Graham, J. (2009). Planet of the Durkheimians, where community, authority, and sacredness are foundations of morality. In J. T. Jost, A. C. Kay, \& H. Thorisdottir (Eds.), Social and psychological bases of ideology and system justification., Series in political psychology (pp. 371-401). New York, NY US: Oxford University Press.

Haidt, J., \& Joseph, C. (2008). The moral mind: How five sets of innate intuitions guide the development of many culture-specific virtues, and perhaps even modules. In P. Carruthers, S. Laurence, \& S. Stich (Eds.), The innate mind Volume 3: Foundations and the future, Evolution and cognition. (pp. 367-391). New York, NY, US: Oxford University Press.

Harris, L. T., \& Fiske, S. T. (2006). Dehumanizing the Lowest of the Low Neuroimaging Responses to Extreme Out-Groups. Psychological Science, 17, 847-853. doi:10.1111/j.1467-9280.2006.01793.x

Haslam, N. (2006). Dehumanization: An integrative review. Personality and social psychology review, 10, 252-264.

Haslam, N., \& Loughnan, S. (2014). Dehumanization and Infrahumanization. Annual Review of Psychology, 65, 399-423. doi:10.1146/annurev-psych-010213-115045 
Haslam, N., Loughnan, S., Kashima, Y., \& Bain, P. (2009). Attributing and denying humanness to others. European Review of Social Psychology, 19, 55-85.

doi:10.1080/10463280801981645

Hasson, Y., Tamir, M., Brahms, K. S., Cohrs, J. C., \& Halperin, E. (2018). Are Liberals and Conservatives Equally Motivated to Feel Empathy Toward Others? Personality and Social Psychology Bulletin, 0146167218769867. doi:10.1177/0146167218769867

Hayes, A. F. (2013). Introduction to mediation, moderation, and conditional process analysis: $A$ regression-based approach. Guilford Press.

Horberg, E. J., Oveis, C., Keltner, D., \& Cohen, A. B. (2009). Disgust and the moralization of purity. Journal of Personality and Social Psychology, 97, 963-976. doi:10.1037/a0017423

Inbar, Y., Pizarro, D. A., \& Bloom, P. (2012). Disgusting smells cause decreased liking of gay men. Emotion, 12, 23-27. doi:10.1037/a0023984

Janoff-Bulman, R., \& Carnes, N. C. (2013). Surveying the moral landscape: Moral motives and group-based moralities. Personality and Social Psychology Review, 17, 219-236. doi:10.1177/1088868313480274

Janoff-Bulman, R., Sheikh, S., \& Hepp, S. (2009). Proscriptive versus prescriptive morality: Two faces of moral regulation. Journal of Personality and Social Psychology, 96, 521537. doi:10.1037/a0013779

Kervyn, N., Fiske, S. T., \& Yzerbyt, V. Y. (2013). Integrating The Stereotype Content Model (Warmth And Competence) And The Osgood Semantic Differential (Evaluation, Potency, And Activity). European journal of social psychology, 43, 673-681. doi:10.1002/ejsp. 1978

Knobe, J. (2003). Intentional action and side effects in ordinary language. Analysis, 63, 190-194. doi:10.1111/1467-8284.00419

Kohlberg, L. (1976). Moral stages and moralization: The cognitive-developmental approach. In T. Lickona (Ed.), Moral development and behavior: Theory, research, and social issues (pp. 31-53). New York NY: Holt, Rinehart and Winston.

Koleva, S. P., Graham, J., Iyer, R., Ditto, P. H., \& Haidt, J. (2012). Tracing the threads: How five moral concerns (especially Purity) help explain culture war attitudes. Journal of Research in Personality, 46, 184-194. doi:10.1016/j.jrp.2012.01.006

Kteily, N., Hodson, G., \& Bruneau, E. (2016). They see us as less than human: Metadehumanization predicts intergroup conflict via reciprocal dehumanization. Journal of Personality and Social Psychology, 110, 343-370. doi:10.1037/pspa0000044

Low, M., \& Wui, M. G. L. (2015). Moral Foundations and Attitudes Towards the Poor. Current Psychology, 1-11. doi:10.1007/s12144-015-9333-y

Malle, B. F., Guglielmo, S., \& Monroe, A. E. (2012). Moral, cognitive, and social: The nature of blame. In J. P. Forgas, K. Fiedler, \& C. Sedikides (Eds.), Social Thinking and Interpersonal Behavior, Sydney symposium of social psychology (pp. 313-331). New York, NY US: Psychology Press.

Malle, B. F., Guglielmo, S., \& Monroe, A. E. (2014). A theory of blame. Psychological Inquiry, 25, 147-186. doi:10.1080/1047840X.2014.877340

Mooijman, M., Meindl, P., Oyserman, D., Monterosso, J., Dehghani, M., Doris, J. M., \& Graham, J. (2017). Resisting Temptation for the Good of the Group: Binding Moral Values and the Moralization of Self-Control. 
Myers, B., Goodwin, G. P., Latter, R., \& Winstanley, S. (2004). Victim impact statements and mock juror sentencing: The impact of dehumanizing language on a death qualified sample. American Journal of Forensic Psychology, 22, 39-56.

Niemi, L., \& Young, L. (2013). Caring across Boundaries versus Keeping Boundaries Intact: Links between Moral Values and Interpersonal Orientations. PLOS ONE, 8, e81605. doi:10.1371/journal.pone.0081605

Niemi, L., \& Young, L. (2016). When and Why We See Victims as Responsible The Impact of Ideology on Attitudes Toward Victims. Personality and Social Psychology Bulletin, 0146167216653933. doi:10.1177/0146167216653933

Norton, A. T., \& Herek, G. M. (2013). Heterosexuals' attitudes toward transgender people: Findings from a national probability sample of US adults. Sex roles, 68, 738-753.

Noser, A. E., Zeigler-Hill, V., Vrabel, J. K., Besser, A., Ewing, T. D., \& Southard, A. C. (2015). Dark and immoral: The links between pathological personality features and moral values. Personality and Individual Differences, 75, 30-35. doi:10.1016/j.paid.2014.11.010

Opotow, S. (1990). Moral exclusion and injustice: An introduction. Journal of social issues, 46, $1-20$.

Osgood, C. E. (1962). Studies on the generality of affective meaning systems. American Psychologist, 17, 10-28. doi:10.1037/h0045146

Pettigrew, T. F., \& Tropp, L. R. (2006). A meta-analytic test of intergroup contact theory. Journal of Personality and Social Psychology, 90, 751-783. doi:10.1037/00223514.90.5.751

Pettigrew, T. F., \& Tropp, L. R. (2008). How does intergroup contact reduce prejudice? Metaanalytic tests of three mediators. European Journal of Social Psychology, 38, 922-934. doi:10.1002/ejsp.504

Pettit, D., \& Knobe, J. (2009). The Pervasive Impact of Moral Judgment. Mind \& Language, 24, 586-604. doi:10.1111/j.1468-0017.2009.01375.x

Phillips, J., \& Knobe, J. (2009). Moral judgments and intuitions about freedom. Psychological Inquiry, 20, 30-36. doi:10.1080/10478400902744279

Piaget, J. (1965). The moral judgement of the child. New York NY: Free Press.

Rai, T. S., \& Fiske, A. P. (2011). Moral psychology is relationship regulation: Moral motives for unity, hierarchy, equality, and proportionality. Psychological Review, 118, 57-75. doi: $10.1037 / \mathrm{a} 0021867$

Reed, A., \& Aquino, K. F. (2003). Moral identity and the expanding circle of moral regard toward out-groups. Journal of Personality and Social Psychology, 84, 1270-1286. doi:10.1037/0022-3514.84.6.1270

Rottman, J., Kelemen, D., \& Young, L. (2014). Tainting the soul: Purity concerns predict moral judgments of suicide. Cognition, 130, 217-226. doi:10.1016/j.cognition.2013.11.007

Rudman, L. A., \& Mescher, K. (2012). Of Animals and Objects: Men's Implicit Dehumanization of Women and Likelihood of Sexual Aggression. Personality and Social Psychology Bulletin, 38, 734-746. doi:10.1177/0146167212436401

Schein, C., \& Gray, K. (2017). The Theory of Dyadic Morality: Reinventing Moral Judgment by Redefining Harm. Personality and Social Psychology Review, 1088868317698288. doi: $10.1177 / 1088868317698288$

Schnall, S., Haidt, J., Clore, G. L., \& Jordan, A. H. (2008). Disgust as embodied moral judgment. Personality and Social Psychology Bulletin, 34, 1096-1109.

doi:10.1177/0146167208317771 
Smith, I. H., Aquino, K., Koleva, S., \& Graham, J. (2014). The Moral Ties That Bind . . Even to Out-Groups: The Interactive Effect of Moral Identity and the Binding Moral Foundations. Psychological Science, 25, 1554-1562. doi:10.1177/0956797614534450

Strohminger, N., \& Nichols, S. (2015). Neurodegeneration and Identity. Psychological Science, 0956797615592381. doi:10.1177/0956797615592381

Tam, T., Hewstone, M., Cairns, E., Tausch, N., Maio, G., \& Kenworthy, J. (2007). The Impact of Intergroup Emotions on Forgiveness in Northern Ireland. Group Processes \& Intergroup Relations, 10, 119-136. doi:10.1177/1368430207071345

Tendayi, G., Winchester, L., Titshall, L., Chisango, T., Pina, A., \& Russell, R. (2006). Beyond secondary emotions: The infrahumanization of outgroups using human-related and animal-related words. Social Cognition, 24, 753-775. doi:10.1521/soco.2006.24.6.753

Tetlock, P. E., Kristel, O. V., Elson, S. B., Green, M. C., \& Lerner, J. S. (2000). The psychology of the unthinkable: Taboo trade-offs, forbidden base rates, and heretical counterfactuals. Journal of Personality and Social Psychology, 78, 853-870. doi:10.1037//00223514.78.5.853

Turiel, E. (1983). The development of social knowledge: Morality and convention. Cambridge [Cambridgeshire]: Cambridge University Press.

Turiel, E., Killen, M., \& Helwig, C. C. (1987). Morality: Its structure, functions, and vagaries. In J. Kagan \& S. Lamb (Eds.), The emergence of morality in young children (pp. 155-243). Chicago, IL, US: University of Chicago Press.

Van Leeuwen, F., Koenig, B. L., Graham, J., \& Park, J. H. (2014). Moral concerns across the United States: associations with life-history variables, pathogen prevalence, urbanization, cognitive ability, and social class. Evolution and Human Behavior, 35, 464-471. doi:10.1016/j.evolhumbehav.2014.06.005

Van Leeuwen, F., Park, J. H., Koenig, B. L., \& Graham, J. (2012). Regional variation in pathogen prevalence predicts endorsement of group-focused moral concerns. Evolution and Human Behavior, 33, 429-437. doi:10.1016/j.evolhumbehav.2011.12.005

Vezzali, L., Capozza, D., Stathi, S., \& Giovannini, D. (2012). Increasing outgroup trust, reducing infrahumanization, and enhancing future contact intentions via imagined intergroup contact. Journal of Experimental Social Psychology, 48, 437-440. doi:10.1016/j.jesp.2011.09.008

Waytz, A., Dungan, J., \& Young, L. (2013). The whistleblower's dilemma and the fairnessloyalty tradeoff. Journal of Experimental Social Psychology, 49, 1027-1033. doi:10.1016/j.jesp.2013.07.002

Waytz, A., Iyer, R., Young, L., \& Graham, J. (2016). Ideological differences in the expanse of empathy. Social Psychology of Political Polarization, 61-77.

Yilmaz, O., Harma, M., Bahçekapili, H. G., \& Cesur, S. (2016). Validation of the Moral Foundations Questionnaire in Turkey and its relation to cultural schemas of individualism and collectivism. Personality and Individual Differences, 99, 149-154. doi:10.1016/j.paid.2016.04.090

Zeigler-Hill, V., Noser, A. E., Roof, C., Vonk, J., \& Marcus, D. K. (2015). Spitefulness and moral values. Personality and Individual Differences, 77, 86-90. doi:10.1016/j.paid.2014.12.050 